\title{
Irradiation of Miniature
} Fuel Specimens in the High Flux Isotope Reactor

Nuclear Technology

Research and Development 



\section{DISCLAIMER}

This information was prepared as an account of work sponsored by an agency of the U.S. Government. Neither the U.S. Government nor any agency thereof, nor any of their employees, makes any warranty, expressed or implied, or assumes any legal liability or responsibility for the accuracy, completeness, or usefulness, of any information, apparatus, product, or process disclosed, or represents that its use would not infringe privately owned rights. References herein to any specific commercial product, process, or service by trade name, trade mark, manufacturer, or otherwise, does not necessarily constitute or imply its endorsement, recommendation, or favoring by the U.S. Government or any agency thereof. The views and opinions of authors expressed herein do not necessarily state or reflect those of the U.S. Government or any agency thereof. 



\section{SUMMARY}

The Advanced Fuels Campaign (AFC) within the US Department of Energy (DOE) Office of Nuclear Energy is considering several advanced ceramic fuels for use in light water reactors (LWRs) and/or advanced reactor concepts. Advanced fuels, such as uranium carbide (UC), uranium nitride (UN), and uranium silicide $\left(\mathrm{U}_{3} \mathrm{Si}_{2}\right)$ offer increased uranium density and enhanced thermophysical properties compared to conventional $\mathrm{UO}_{2}$ fuel, while maintaining an acceptably high melting point. Enhancements to traditional $\mathrm{UO}_{2}$ are also being considered that would increase the thermal conductivity of the fuel and fission product retention through various additives. However, some of these advanced fuels have very limited information available on their irradiation performance (microstructural evolution, swelling, fission gas release, etc.), particularly for the range of temperature and burnup that are relevant for LWR fuel pins. To address this issue, Oak Ridge National Laboratory has developed an experimental facility to irradiate miniature fuel specimens in the High Flux Isotope Reactor (HFIR). The small size of the fuel specimens simplifies the design, analysis, and post-irradiation evaluations. Post-irradiation examination will provide basic data on the stability and behavior of advanced fuels as a function of temperature and burnup. This report briefly summarizes the experiment facility design concept and the assembly of the first set of experiments. The experiment contains six different types of UN-based fuel kernels UN TRISO particles with varying densities, impurity levels, and burnable absorber contents. The experiments were successfully assembled, welded, evaluated, and delivered to the HFIR along with a complete quality assurance fabrication package. Pictures of the assembly process are included in this report. The experiment is planned for insertion into the HFIR during cycle 480 (June 2018). 

June 28, 2018 


\section{CONTENTS}

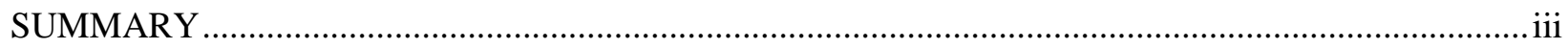

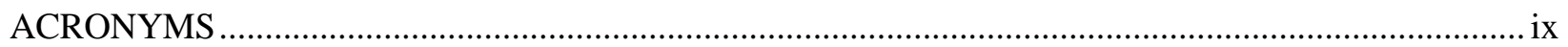

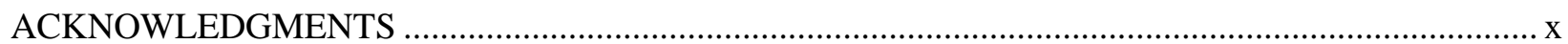

1. OBJECTIVE

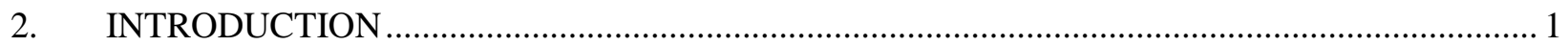

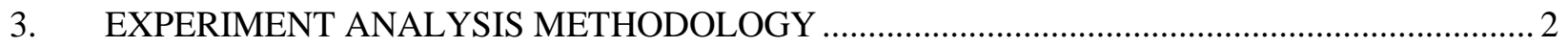

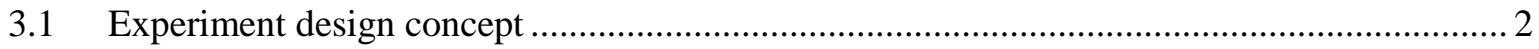

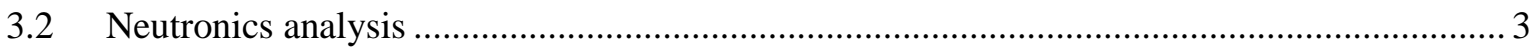

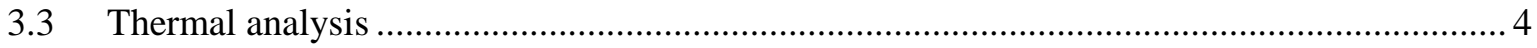

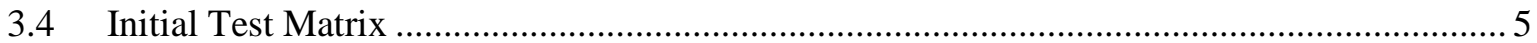

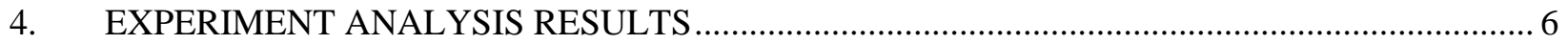

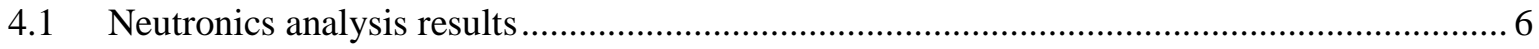

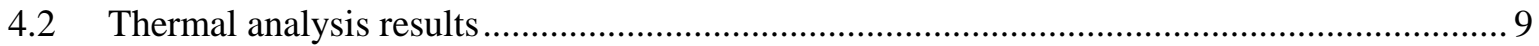

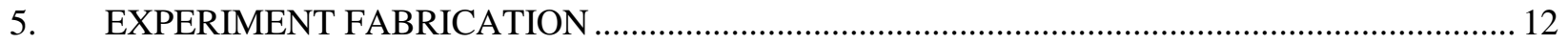

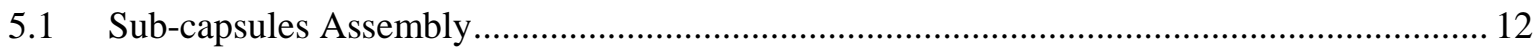

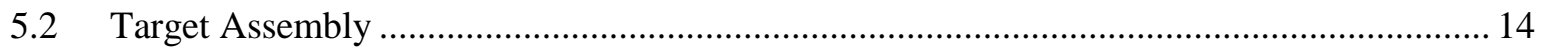

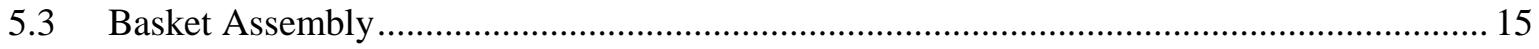

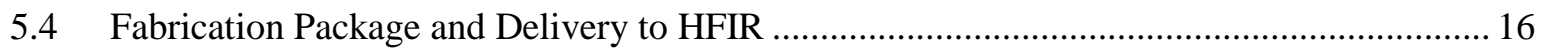

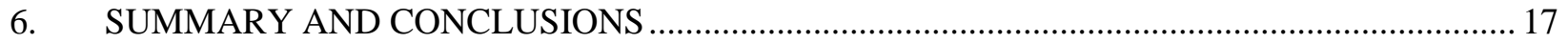

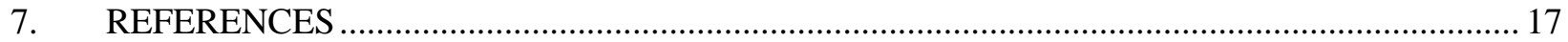

APPENDIX A. FABRICATION AND QUALITY ASSURANCE DOCUMENTATION FOR

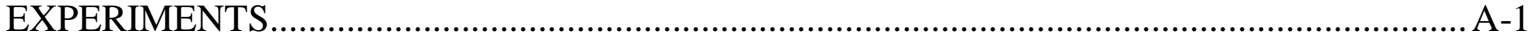




\section{FIGURES}

Figure 1. Irradiation design concept.

Figure 2. 3-D solid model for a single irradiation target and the resulting finite element mesh with 1/4-symmetry.

Figure 3. Polished cross-sectional image of UN TRISO particle (left) and image of UN kernels (right).

Figure 4. Heat generation rate (HGR) in titanium components vs. axial distance from the core midplane (z) at beginning of cycle (BOC) and end of cycle (EOC). Exponential fits to the calculated data are shown with goodness of fit parameter $\mathrm{R}^{2}$.

Figure 5. Heat generation rate (HGR) in the molybdenum tubes vs. axial distance from the core midplane (z) at beginning of cycle (BOC) and end of cycle (EOC). Exponential fits to the calculated data are shown with goodness of fit parameter $\mathrm{R}^{2}$.

Figure 6. Calculated fuel fission rate (solid lines) and burnup (dashed lines) vs. number of HFIR cycles for three different enrichment levels. Results are for fuel located at the core midplane in radial targets oriented toward the HFIR core.

Figure 7. EOC temperature contours (in ${ }^{\circ} \mathrm{C}$ ) with peak fuel heating rates for a target loaded in an inner radial position with six UN sub-capsules. Results show all target components (top), a single center sub-assembly (middle), the fuel kernels from the center subassembly (bottom left), and the temperature monitor from the center sub-assembly (bottom right).

Figure 8. Design gas gaps between the sub-capsules and the target housing vs. axial distance from the core midplane for inner radial target positions and outer radial target positions.

Figure 9. Fuel temperature vs. distance from the core midplane $(\mathrm{z})$ for an inner radial target position at beginning of cycle (BOC) and end of cycle (EOC). Error bars indicate the extreme fuel temperatures at each location.

Figure 10. Fuel temperature vs. distance from the core midplane (z) for an outer radial target position at beginning of cycle (BOC) and end of cycle (EOC). Error bars indicate the extreme fuel temperatures at each location.

Figure 11. Sub-capsule part layout (top), kernel fuel inside a cup (bottom left), and TRISO particle fuel inside a different cup (bottom right)....

Figure 12. Top view of a loaded sub-capsule without its end cap (left) and welded sub-capsules (right).

Figure 13. Parts layout for target assembly MF01: individual parts layout (top) and assembly of centering thimbles and sub-capsules (bottom).

Figure 14. Radiograph of targets MF01 and MF02. .15

Figure 15. Parts layout for the basket assembly.

Figure 16. Insertion of a capsule in the basket assembly (left), and top-down view of the basket after loading all targets (right). 


\section{TABLES}

Table 1. Materials and property references for thermal analyses. ..........................................................5

Table 2. Test matrix for first mini fuel irradiation experiment. .............................................................. 6

Table 3. Peak midplane heat generation rates at beginning of cycle (BOC) and end of cycle

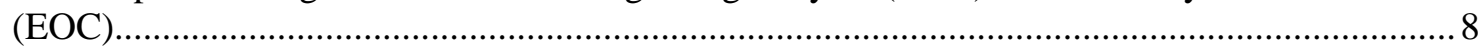




\section{ACRONYMS}

$\begin{array}{ll}\text { AFC } & \begin{array}{l}\text { Advanced Fuels Campaign } \\ \text { Department of Energy, } \\ \text { Office of Nuclear Energy }\end{array} \\ \text { EABD } & \begin{array}{l}\text { Experiment authorization } \\ \text { basis document }\end{array} \\ \text { HFIR } & \text { High Flux Isotope Reactor } \\ \text { HGR } & \text { Heat generation rate } \\ \text { LWR } & \text { Light water reactor } \\ \text { ORNL } & \text { Oak Ridge National } \\ \text { PIE } & \text { Laboratory } \\ \text { PWR } & \text { Post-irradiation examination } \\ \text { QA } & \text { Pressurized water reactor } \\ \text { SiC } & \text { Quality assurance } \\ \text { TRISO } & \text { Silicon carbide } \\ \text { UN } & \text { Tri-structural isotropic } \\ \text { VXF } & \text { Uranium nitride }\end{array}$




\section{ACKNOWLEDGMENTS}

This work was supported by the US Department of Energy Office of Nuclear Energy (DOE-NE) Advanced Fuels Campaign (AFC). Neutron irradiation in the High Flux Isotope Reactor (HFIR) is made possible by the Office of Basic Energy Sciences, US DOE. The report was authored by UT-Battelle under Contract No. DE-AC05-00OR22725 with the US DOE. Alicia Raftery and David Bryant performed most of the capsule assembly work. Joel McDuffee and Josh Peterson-Droogh performed reviews of the thermal and neutronic calculations that support this work. 


\section{OBJECTIVE}

The objective of this work is to initiate the first series of miniature fuel specimen irradiations in the High Flux Isotope Reactor (HFIR) to facilitate rapid and cost-effective irradiation of novel fuel concepts. This first experiment will provide basic data on the irradiation performance of uranium nitride (UN) fuel kernels at relevant light water reactor temperatures.

\section{INTRODUCTION}

Qualification of new nuclear fuel materials requires a scientific understanding of fuel behavior including irradiation performance. Traditionally, irradiation performance data has been acquired through many integral fuel irradiation experiments where full-size fuel pellets are tested under conditions that closely match those of the intended application. While this approach is logical, it is very expensive and time consuming, particularly when considering a large test matrix that could include variations in fuel centerline temperature, burnup, and power history or variations in the fuel itself such as composition, enrichment, grain size, impurities, or non-stoichiometries. Furthermore, the large number of variables that affect fuel performance make it difficult to develop fundamental models of various phenomena from integral fuel tests, which often have many independent variables that cannot be well-controlled. Therefore, there exists a need to be able to perform well-controlled separate effects irradiation testing of a wide range of new fuel concepts within a reasonable time and cost. Ideally these tests would be accelerated to accumulate burnup quickly. In addition, the testing platform should be flexible so that a range of fuel composition, enrichment, and even geometry can be tested without requiring detailed designs and analyses that are specific to each fuel concept.

This work reports on the successful implementation of a new capability for performing accelerated separate effects irradiation testing of miniature ("mini") fuel specimens in the HFIR at Oak Ridge National Laboratory (ORNL). The design concept places the mini fuel specimens inside individually sealed subcapsules inside steel targets in the reflector of the reactor. Temperature is controlled by sizing an insulating gas gap between the sub-capsules and the target housing. Reducing the size of the fuel allows for very high fission rates (on a per unit mass basis) without prohibitively large temperature gradients. Furthermore, the small fuel mass results in the total heat generated in each sub-capsule being dominated by gamma heating in the structure instead of fission in the fuel itself. This essentially decouples the fuel temperature from the fission rate. This work describes the design concept, neutronic and thermal analyses, and the fabrication, assembly, and delivery of the first set of experiments tested in the HFIR. 


\section{EXPERIMENT ANALYSIS METHODOLOGY}

\subsection{Experiment design concept}

Three-dimensional (3D) models of the experiment facility and an irradiation target are shown in Figure 1. The irradiation facility can accommodate as many as nine irradiation targets that are cooled at their outer surface by the reactor primary coolant. The irradiation facility is oriented so that the notch in the basket is pointed toward the reactor core. This allows for two of the three radial positions (positions 2 and 3) to be positioned at the same radial distance from the reactor core. These positions are expected to receive essentially the same neutron flux and gamma heating. Radial position 1 faces away from the core. Three targets are stacked vertically in each of the three radial target positions. Axial target positions 1, 2, and 3 correspond to the bottom, middle, and top positions, respectively. Each target contains six sealed titanium sub-capsules, each of which contains either four bare fuel kernels or six TRISO particles inside a molybdenum cup. Thimbles on either end of the sub-capsules insure centering of the sub-capsules within the target housing. Compression springs at both ends of the target housing keep the stacked parts in good contact. The sub-capsules each contain fuel specimens and SiC passive thermometry. The fuel specimens are surrounded by the molybdenum cup and tube to prevent chemical interaction with the titanium subcapsule. A small hole in the sub-capsule end cap is used to perform the final seal weld of the sub-capsule. Temperature is controlled by varying the composition and size of the gas gap between the sub-capsule and the target housing. This gap depends primarily on gamma heating in the sub-capsule assembly components. The $\mathrm{SiC}$ thermometer is used to evaluate the irradiation temperature post-irradiation using dilatometry [1]. Experiments are irradiated in inner small vertical experiment facilities in the HFIR reflector. This first set of experiments were designed for an irradiation temperature of $500^{\circ} \mathrm{C}$. 


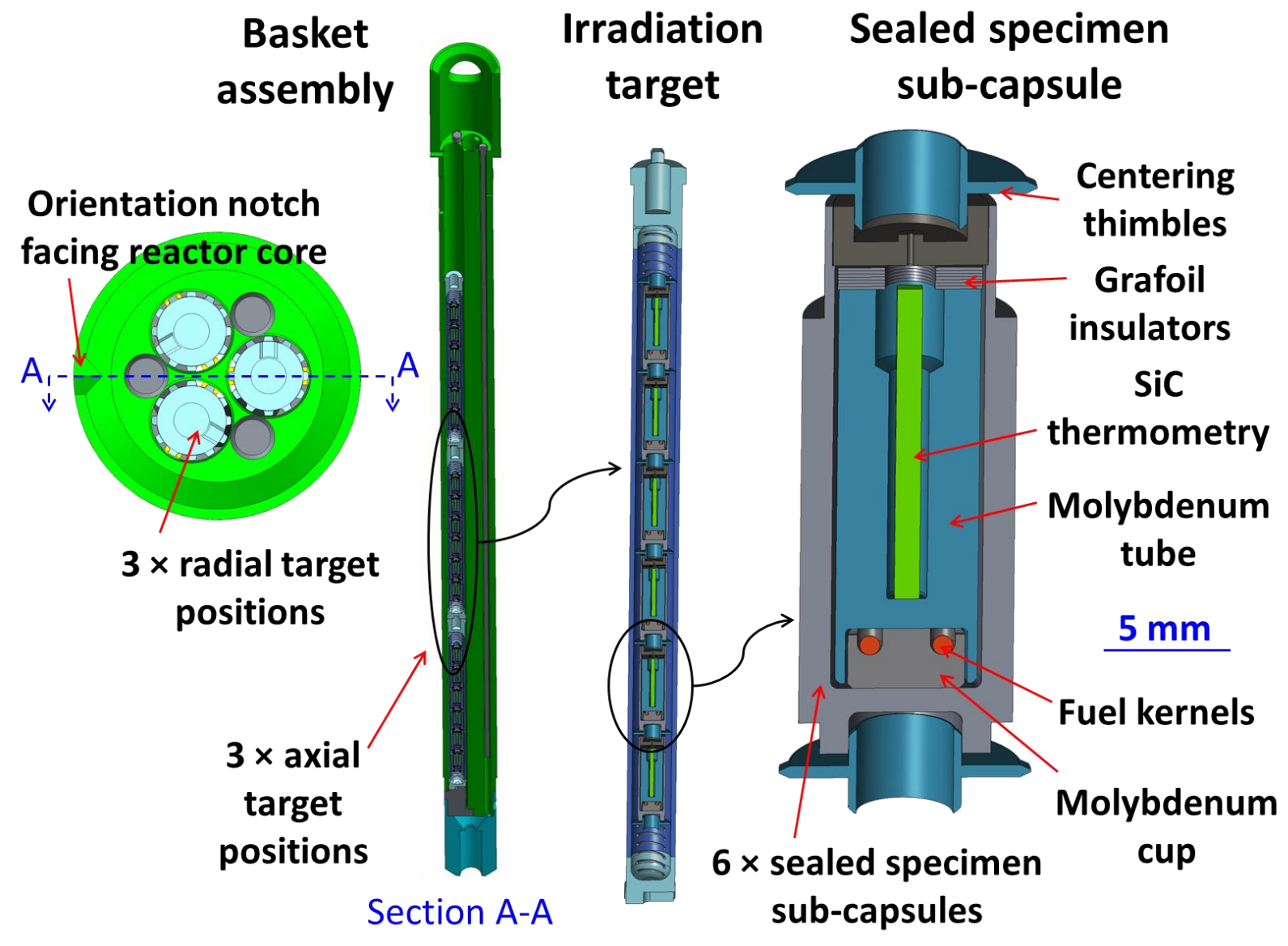

Figure 1. Irradiation design concept.

\subsection{Neutronics analysis}

Neutronics calculations are carried out to assess neutron and gamma heating rates in the fuel and capsule components to provide input to subsequent thermal analyses, as well as to generate initial fuel irradiation behavior predictions in terms of the fuel burnup profile. This is accomplished using the MCNP5 and SCALE software code packages. The MCNP calculations are based on existing beginning and end of cycle models [2] of the HFIR with cycle 400 experimental loading with some modifications to represent the new experimental assembly. The heat generation evaluation must account for contributions from fission neutrons (prompt and delayed), prompt fission photons, delayed photons from fission product decay, $\alpha$ and $\beta$ decay heat, and photon heating from local activation product decay. Prompt fission neutron and photon heating is calculated directly from MCNP transport simulations using an established fission neutron source distribution definition (with both neutron and photon tracking activated to implicitly yield an appropriate fission photon source distribution) [3]. Heat generation from these sources is then tallied in all experiment components. To account for heat generation from fission product decay photons originating in the HFIR fuel, a separate calculation is performed with a fixed photon source distribution definition reflecting the gamma emission rate and spectrum due to these accumulated fission products [3]. Activation and decay calculations are carried out using the ORIGEN module of the SCALE code package. Problem- 
specific ORIGEN cross section data are generated with the COUPLE cross section processing module using 238-group neutron flux tallies from MCNP, enabling extended irradiation calculations with ORIGEN. These calculations yield local alpha and beta decay heating from activation products, as well as activation product gamma emission rates and spectra. This latter information is used to construct a local activation gamma source distribution definition for a final MCNP calculation assessing heat generation in the experimental capsule components from this photon source.

This methodology is implemented as described above for a thorough assessment of heat generation, burnup accumulation, and fission gas production for the first cycle of irradiation. These procedures may be extended with some modifications to assess later cycles of irradiation as well. Specifically, a Python script is employed to automate the coupling of flux magnitude and spectral results from MCNP to ORIGEN for depletion and decay assessment, followed by updating the MCNP models using the isotopics determined from ORIGEN [3]. In this manner, the irradiation experiment may be simulated for multiple cycles (currently up to 30); however, challenges remain with respect to reconciling the necessary computational time and rigor with the statistical reliability of the results. Efforts are underway to ameliorate these uncertainties by simplifying the temporal structure of the transport-depletion coupling sequence, generating reliable fixed representative cross section data, and by comparison against the SHIFT stochastic transport code. However, regardless of the precision of long-term burnup predictions, scoping studies have indicated that for fuel with the maximum allowable ${ }^{235} \mathrm{U}$ enrichment $(2.5 \mathrm{wt} \%)$, fuel heat generation decreases monotonically with increasing burnup. Therefore, fuel heat generation rates at the beginning of the first irradiation cycle are sufficient to bound the thermal design of the experimental assembly.

\subsection{Thermal analysis}

Thermal finite element calculations are performed using the ANSYS software code package with custom macros for determining thermal contact conductance between components and heat transfer through small movable (due to thermal expansion) gas gaps [4]. Figure 2 shows the CAD model for a single irradiation target and the resulting mesh after importing into ANSYS and applying 1/4-symmetry. Minor components such as the target end caps, compression springs, fillets, and welds were removed. The remaining features were meshed with 20-node 3-D thermal solid elements with a nominal mesh size of 0.4 mm.

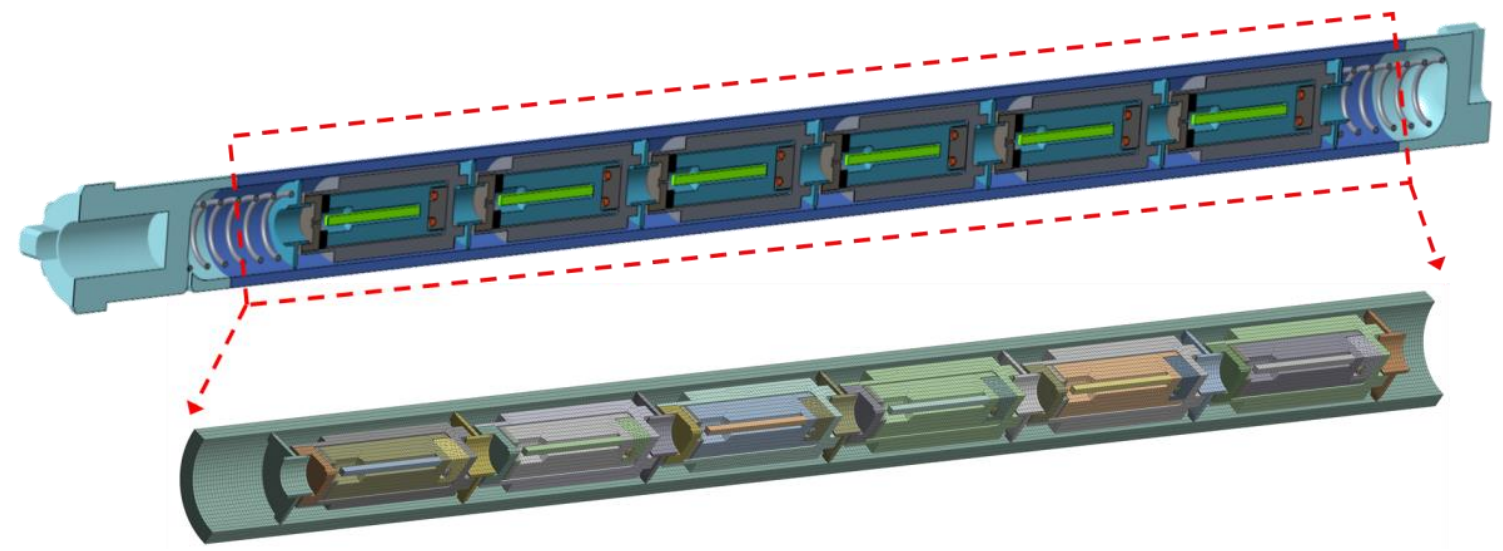

Figure 2. 3-D solid model for a single irradiation target and the resulting finite element mesh with 1/4symmetry. 
Internal heat generation is applied to all components using the heat generation rates calculated in section 4.1. A convection boundary condition is applied to the outer surface of the target housing. Values of $44.8 \mathrm{~kW} \mathrm{~m} \mathrm{~K}^{-2} \mathrm{~K}^{-1}$ and $58^{\circ} \mathrm{C}$ were used for the convection heat transfer coefficient and bulk coolant temperature, respectively. These numbers were determined using RELAP5 for a previous fueled VXF irradiation experiment using the same facility. While the effects of fuel swelling and fission gas release are not considered in the thermal analyses, these effects are not expected to be significant since the fuel specimens are small $\left(\sim 0.3 \mathrm{~mm}^{3}\right)$, and heat is primarily transferred via conduction from the bottom of the fuel specimens to the cup and then through the sub-capsules. The effects of thermal expansion are considered in the thermal contact conductance. The sub-capsule outer diameters and the fill gas can be varied to achieve the desired fuel temperatures.

Temperature-dependent material properties are used for all materials. Dose (or burnup)-dependent properties are used for SiC and UN. Some properties of the fuels also include porosity dependence. Table 1 summarizes the materials that are included in the thermal model and the references used for the material properties.

Table 1. Materials and property references for thermal analyses.

\begin{tabular}{|l|l|l|}
\hline Material & Components & Property references \\
\hline Titanium & Sub-capsules, centering thimbles & {$[5-7]$} \\
\hline Silicon carbide & Thermometry & {$[6,8]$} \\
\hline 304 stainless steel & Target housings & {$[6,9]$} \\
\hline Molybdenum & Tubes, cups & {$[6,7]$} \\
\hline UN & Fuel kernels & {$[10-15]$} \\
\hline Grafoil & Insulators & {$[16]$} \\
\hline
\end{tabular}

\subsection{Initial Test Matrix}

This first mini fuel experiment will test UN fuel in the form of bare kernels and TRISO particles. Images of UN kernels and a UN TRISO particle are shown in Figure 3. The test matrix is summarized in Table 2. All fuel uses either natural or depleted uranium. For the kernels, several different carbon impurity levels and kernels densities are included. Some kernels include burnable absorbers (Gd) with varying absorber content. More details regarding the fuel fabrication can be found in previous work [17, 18].
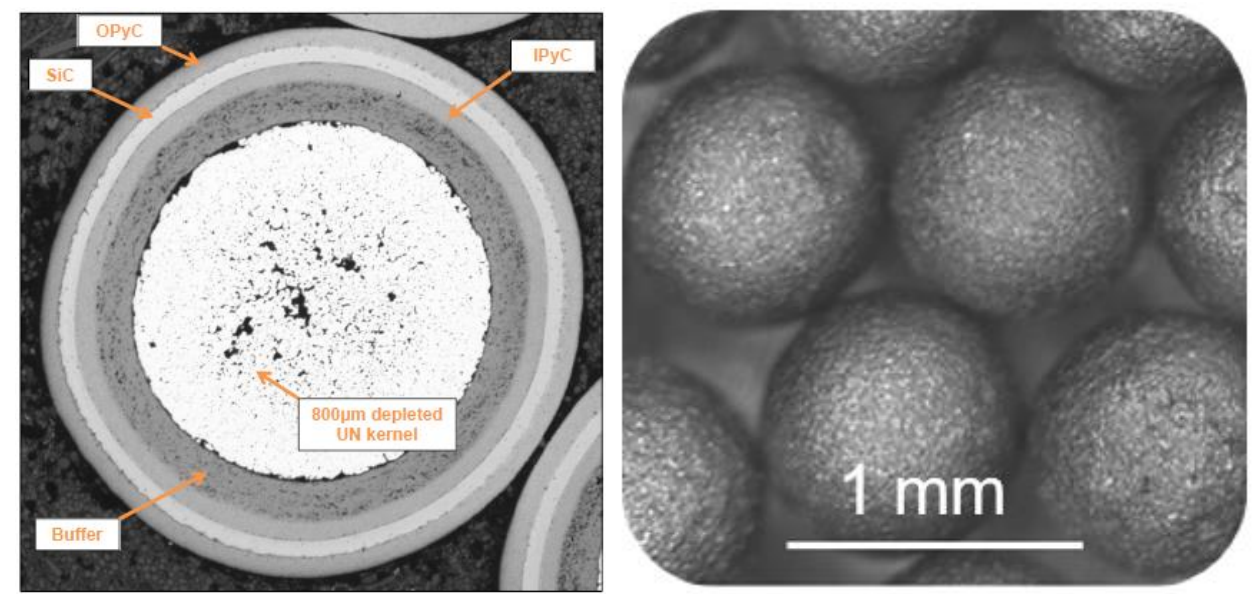

Figure 3. Polished cross-sectional image of UN TRISO particle (left) and image of UN kernels (right). 
Table 2. Test matrix for first mini fuel irradiation experiment.

\begin{tabular}{|c|c|c|c|}
\hline Fuel form & $\begin{array}{c}\text { Kernel theoretical } \\
\text { density }\end{array}$ & $\begin{array}{c}{ }^{235} \text { U Enrichment } \\
\text { (wt \%) }\end{array}$ & $\begin{array}{c}\text { Target burnup } \\
\text { (\% FIMA) }\end{array}$ \\
\hline $\mathrm{UC}_{0.20} \mathrm{~N}_{0.80}$ kernels & $94.9 \%$ & $0.22 \%$ & \\
\hline $\mathrm{UC}_{0.15} \mathrm{~N}_{0.85}$ kernels & $90.6 \%$ & $0.71 \%$ & \multirow{2}{*}{$1 \%, 6 \%$} \\
\hline $\mathrm{UC}_{0.20} \mathrm{~N}_{0.80}$ kernels & $90.9 \%$ & $0.22 \%$ & \\
\hline $\begin{array}{c}\mathrm{U}_{0.89} \mathrm{Gd}_{0.11} \mathrm{C}_{0.11} \mathrm{~N}_{0.89} \\
\text { kernels }\end{array}$ & $92.0 \%$ & $0.71 \%$ & \\
\hline $\begin{array}{c}\mathrm{U}_{0.98} \mathrm{Gd}{ }_{0.02} \mathrm{C}_{0.15} \mathrm{~N}_{0.85} \\
\text { kernels }\end{array}$ & $93.6 \%$ & $0.71 \%$ & \\
\hline $\begin{array}{c}\mathrm{UC}_{0.20} \mathrm{~N}_{0.80} \mathrm{TRISO} \\
\text { particles }\end{array}$ & $87.2 \%$ & $0.22 \%$ & \\
\hline
\end{tabular}

\section{EXPERIMENT ANALYSIS RESULTS}

\subsection{Neutronics analysis results}

Figure 4 and Figure 5 show predicted heat generation rates (HGRs) in the titanium components and the molybdenum tubes as a function of distance from the core midplane (z). Results are shown for the two radial target positions that face toward the HFIR core. Results are shown at beginning of cycle (BOC) and end of cycle (EOC) along with an exponential fit to each data set. Table 3 summarizes peak heating rates at the axial midplane of the core (the center axial target position) for all materials at BOC and EOC. Structural heat generation rates increase by $10-15 \%$ from BOC to EOC. 


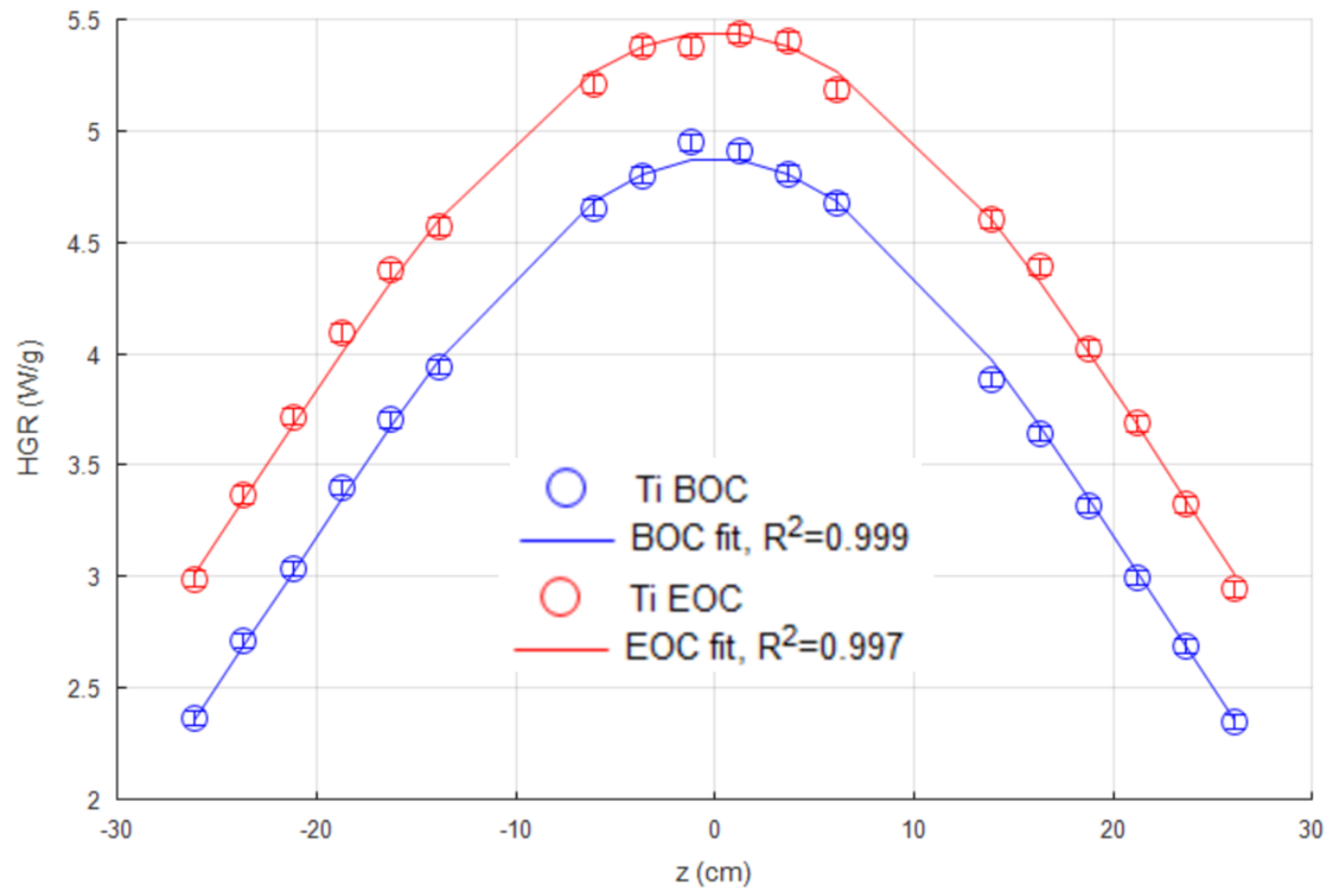

Figure 4. Heat generation rate (HGR) in titanium components vs. axial distance from the core midplane (z) at beginning of cycle (BOC) and end of cycle (EOC). Exponential fits to the calculated data are shown with goodness of fit parameter $\mathrm{R}^{2}$.

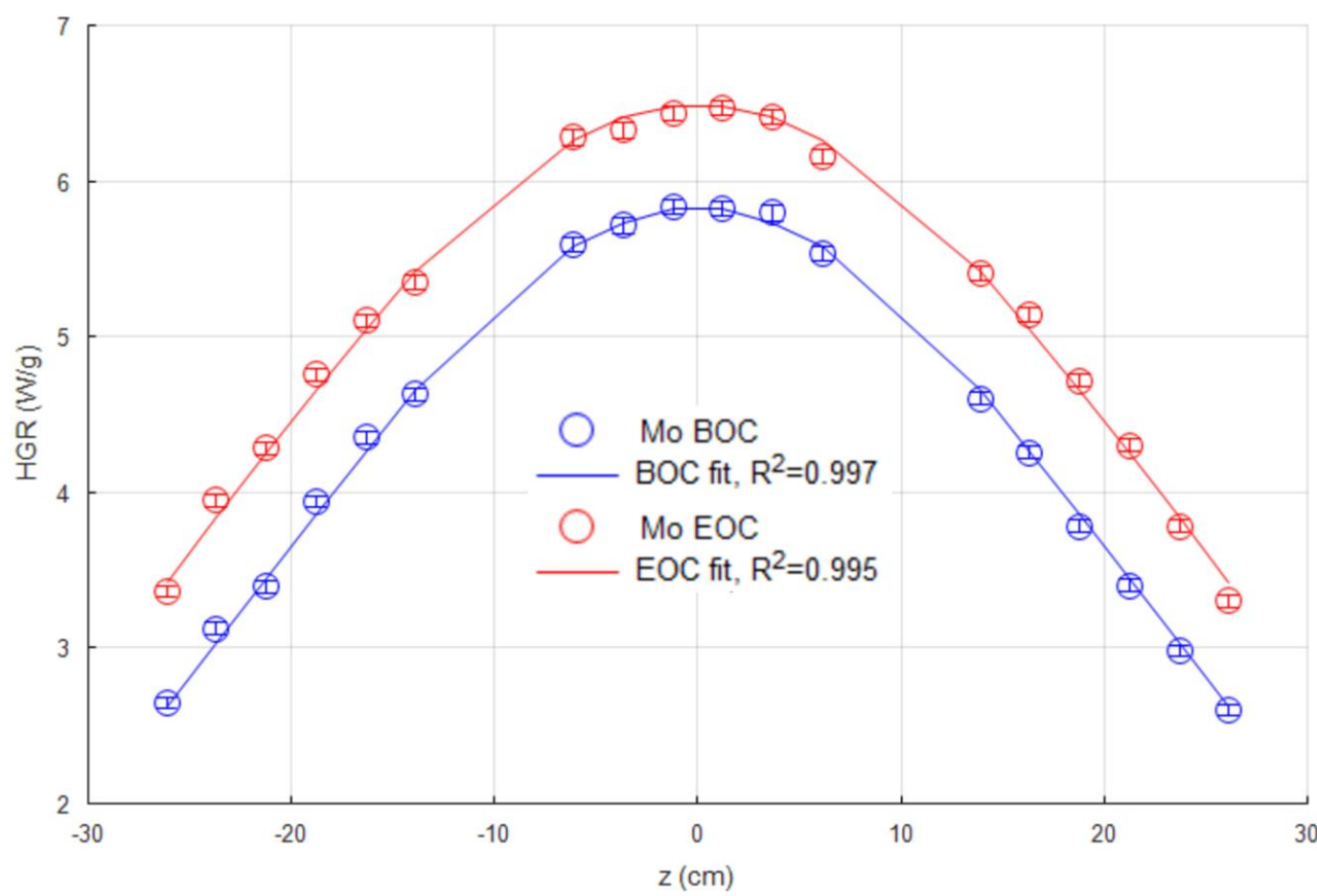

Figure 5. Heat generation rate (HGR) in the molybdenum tubes vs. axial distance from the core midplane (z) at beginning of cycle (BOC) and end of cycle (EOC). Exponential fits to the calculated data are shown with goodness of fit parameter $\mathrm{R}^{2}$. 
Table 3. Peak midplane heat generation rates at beginning of cycle (BOC) and end of cycle (EOC).

\begin{tabular}{|l|c|c|}
\hline \multirow{2}{*}{ Component } & \multicolumn{2}{|c|}{ Peak heat generation $(W / g)$} \\
\cline { 2 - 3 } & \multicolumn{2}{|c|}{$156.3 \pm 0.5^{1}$} \\
\hline UN fuel with $0.22 \%{ }^{235} \mathrm{U}$ & $4.52 \pm 0.10$ & $4.92 \pm 0.12$ \\
\hline Stainless steel target & $4.87 \pm 0.18$ & $5.44 \pm 0.22$ \\
\hline $\begin{array}{l}\text { Titanium sub-capsules and } \\
\text { centering thimbles }\end{array}$ & $5.83 \pm 0.53$ & $6.49 \pm 0.60$ \\
\hline Molybdenum cup & $6.07 \pm 0.29$ & $6.75 \pm 0.34$ \\
\hline Molybdenum tube & $3.98 \pm 0.28$ & $4.35 \pm 0.31$ \\
\hline Silicon carbide thermometry & $3.99 \pm 0.37$ & $4.38 \pm 0.42$ \\
\hline Grafoil & \multicolumn{3}{|c|}{} \\
\hline $\begin{array}{l}{ }^{1} \text { Maximum heat generation rate over all cycles. Figure } \\
\text { 6 shows how the fuel heating rate varies over time. }\end{array}$ \\
\hline
\end{tabular}

The fuel heating rate changes significantly over time due to burnup of the initial ${ }^{235} \mathrm{U}$ and breeding of fissile Pu isotopes. Figure 6 shows $\mathrm{UN}$ fuel fission heating rates and accumulated burnup (in percent fission of initial metal atoms, or FIMA) vs. the number of HFIR cycles for depleted uranium $\left(0.22 \%{ }^{235} \mathrm{U}\right)$, natural uranium $\left(0.73 \%{ }^{235} \mathrm{U}\right)$, and low-enriched uranium $\left(2.5 \%{ }^{235} \mathrm{U}\right)$. The calculated fuel heating rates and burnup use spatially-dependent total neutron flux and effective 1-group cross sections calculated from a highly rigorous MCNP run at the midpoint of the first irradiation cycle. This approach minimizes statistical uncertainties in the inputs to the depletion analysis, which assumes that the total neutron flux and the neutron flux energy spectra do not change significantly from cycle to cycle. This assumption seems reasonable given the small size of the fuel, which limits the impact of fuel transmutation on the neutron flux energy spectrum. Fuel heating rates do not change significantly after 5-7 cycles when an equilibrium is reached between breeding and burning of Pu isotopes and the majority of the ${ }^{235} \mathrm{U}$ has been burned. Based on these results, it is anticipated that LWR discharge burnups of 6\% FIMA can be achieved within 16 irradiation cycles, and that lesser burnups of 1\% FIMA can be achieved within 4 cycles for fuel with depleted uranium. These predictions are to be compared against explicit long-term depletion calculations using the SHIFT code. 


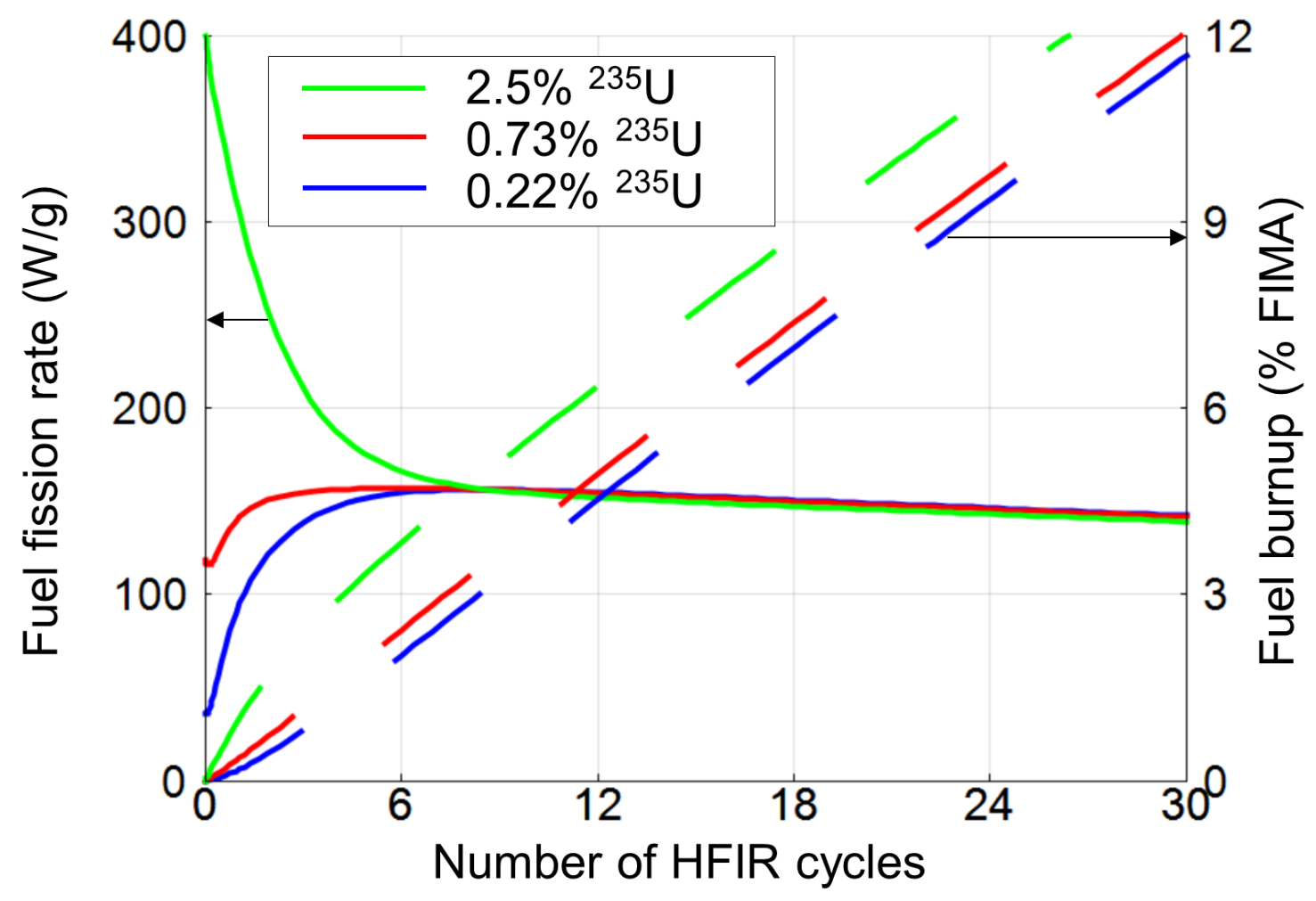

Figure 6. Calculated fuel fission rate (solid lines) and burnup (dashed lines) vs. number of HFIR cycles for three different enrichment levels. Results are for fuel located at the core midplane in radial targets oriented toward the HFIR core.

\subsection{Thermal analysis results}

Figure 7 shows temperature contours for a target containing UN fuel kernels with depleted uranium. These temperatures were calculated using EOC structural HGRs and peak fuel heating rates. The fill gas is a $40.5 \% \mathrm{He}$, Ar balance mixture. Despite the accelerated nature of the testing (i.e., high fuel fission rates), the temperature gradients in the fuel are relatively low $\left(22^{\circ} \mathrm{C}\right)$ because of the small fuel size. The passive $\mathrm{SiC}$ temperature monitors have an average temperature of approximately $480^{\circ} \mathrm{C}\left(\sim 70^{\circ} \mathrm{C}\right.$ lower than the fuel temperatures) with temperature gradients of only $4^{\circ} \mathrm{C}$. The passive $\mathrm{SiC}$ temperature monitors will be used to confirm the irradiation temperatures. 

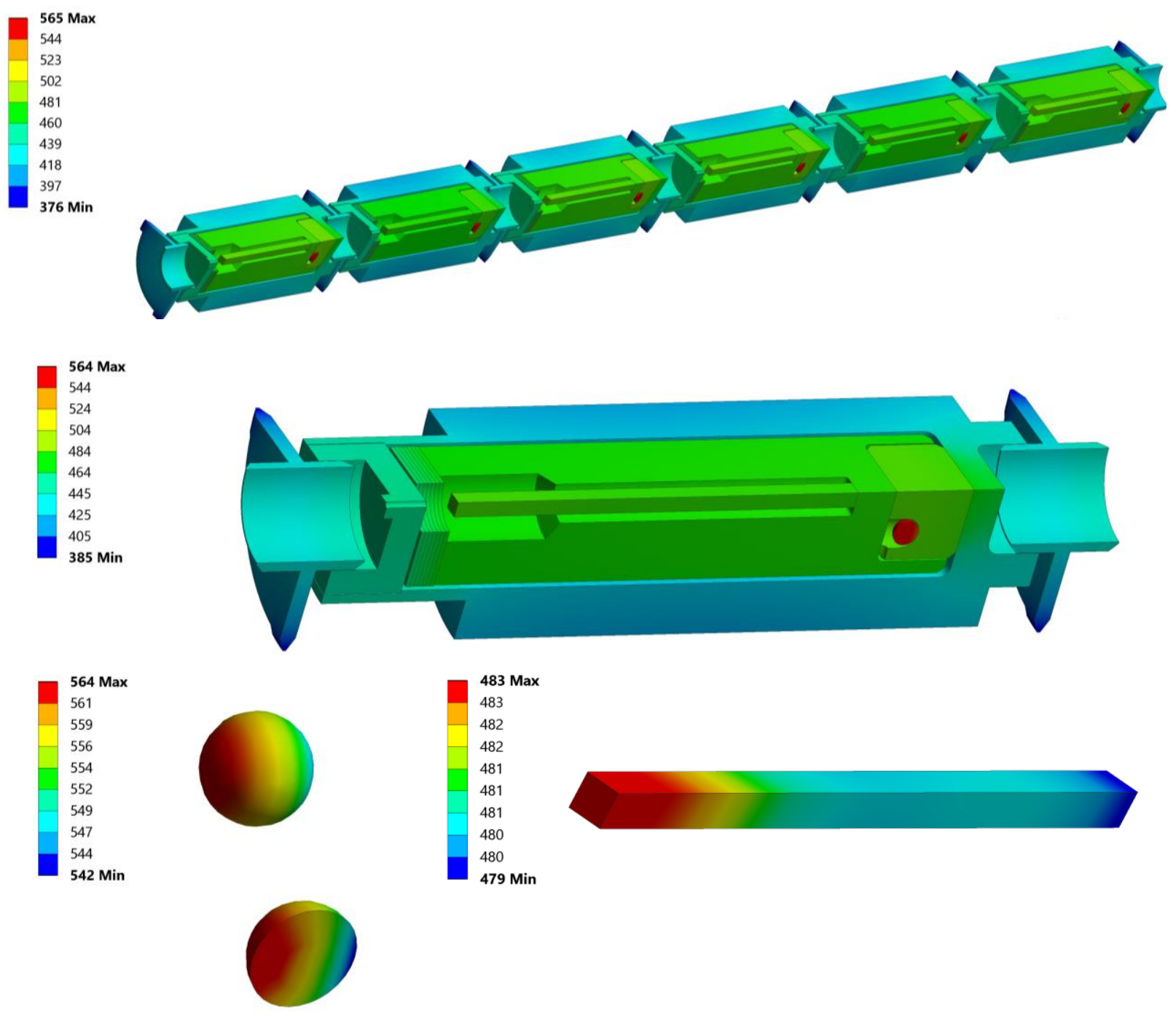

Figure 7. EOC temperature contours $\left(\right.$ in $\left.{ }^{\circ} \mathrm{C}\right)$ with peak fuel heating rates for a target loaded in an inner radial position with six UN sub-capsules. Results show all target components (top), a single center sub-assembly (middle), the fuel kernels from the center sub-assembly (bottom left), and the temperature monitor from the center sub-assembly (bottom right).

Because the target temperature for all fuel specimens is approximately $500^{\circ} \mathrm{C}$ and there exist significant spatial gradients in the HGRs, the sub-capsule-to-housing gas gaps are adjusted to keep all fuel temperatures approximately the same. Figure 8 shows the design gas gaps vs. axial position for both inner radial target positions and outer radial target positions. Figure 9 and Figure 10 show the calculated temperatures for all fuel specimens at BOC with the minimum expected fuel fission rate and at EOC with peak fuel fission rates. The error bars in these figures indicate the maximum and minimum temperatures of the fuel at each location. The BOC and EOC cases that were evaluated cover the entire range of fuel temperatures that are expected during the experiment. All fuel temperatures remain within $75^{\circ} \mathrm{C}$ of the $500^{\circ} \mathrm{C}$ design temperature with most fuel temperatures remaining within $50^{\circ} \mathrm{C}$. 


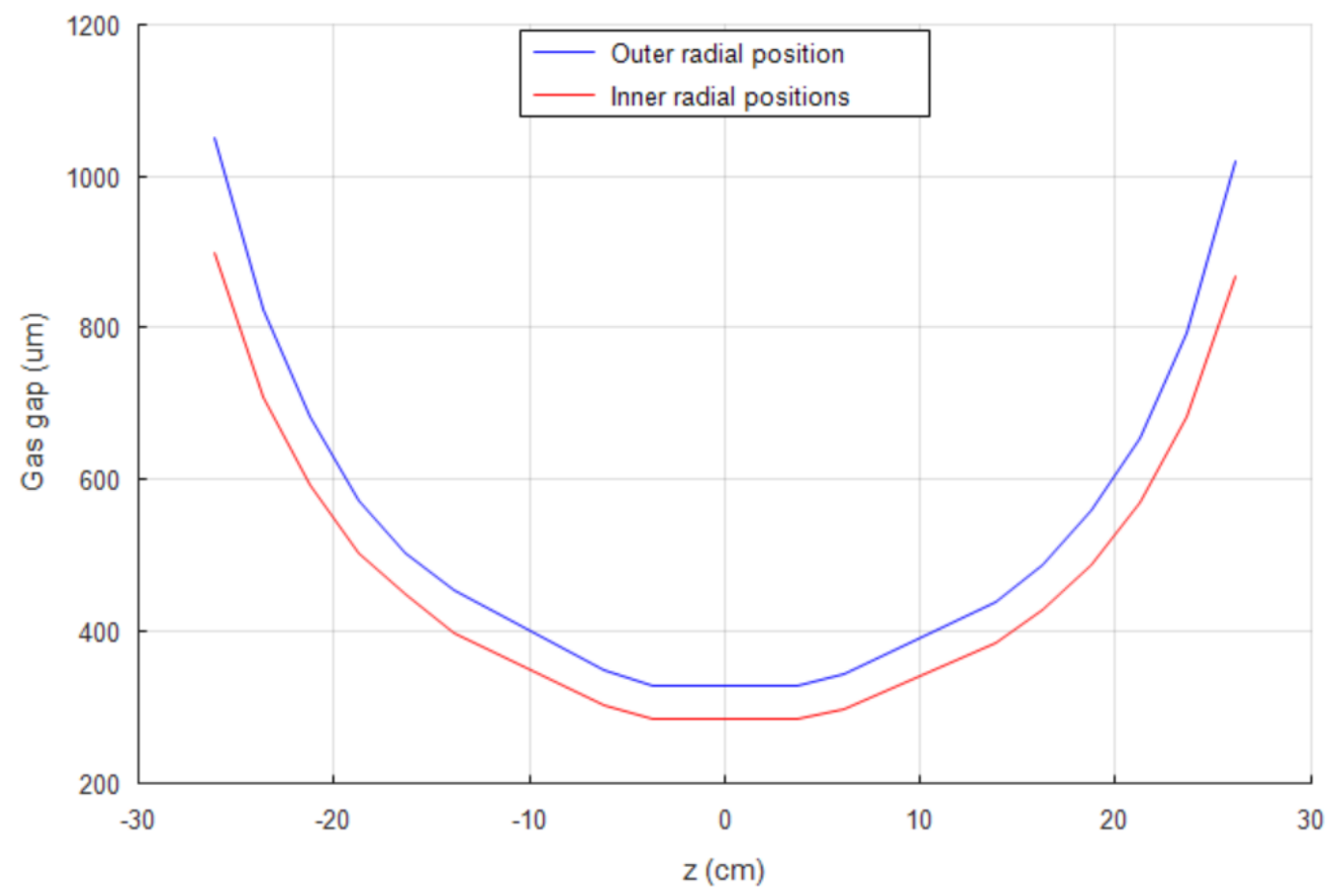

Figure 8. Design gas gaps between the sub-capsules and the target housing vs. axial distance from the core midplane for inner radial target positions and outer radial target positions.

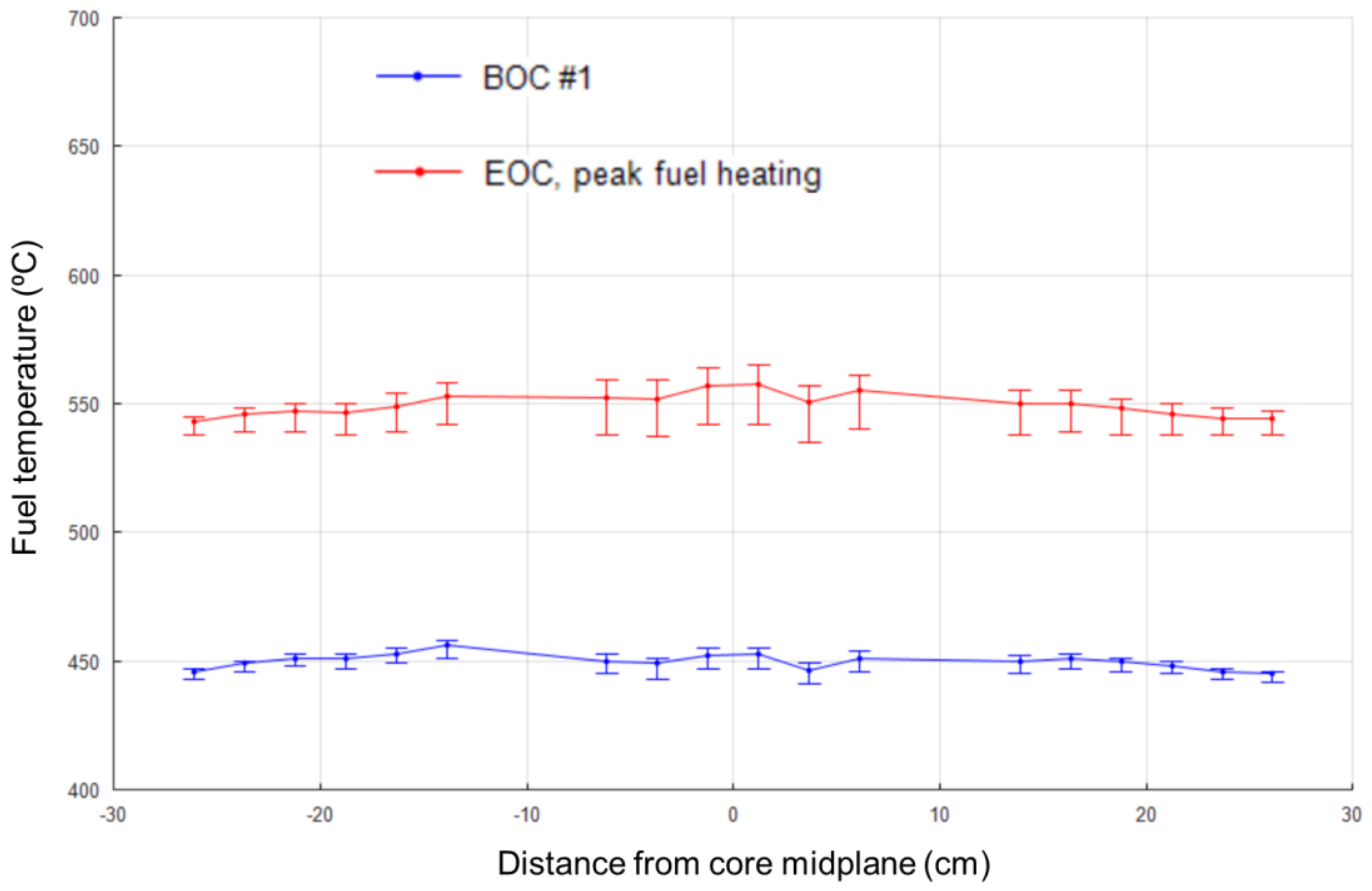

Figure 9. Fuel temperature vs. distance from the core midplane (z) for an inner radial target position at beginning of cycle (BOC) and end of cycle (EOC). Error bars indicate the extreme fuel temperatures at each location. 


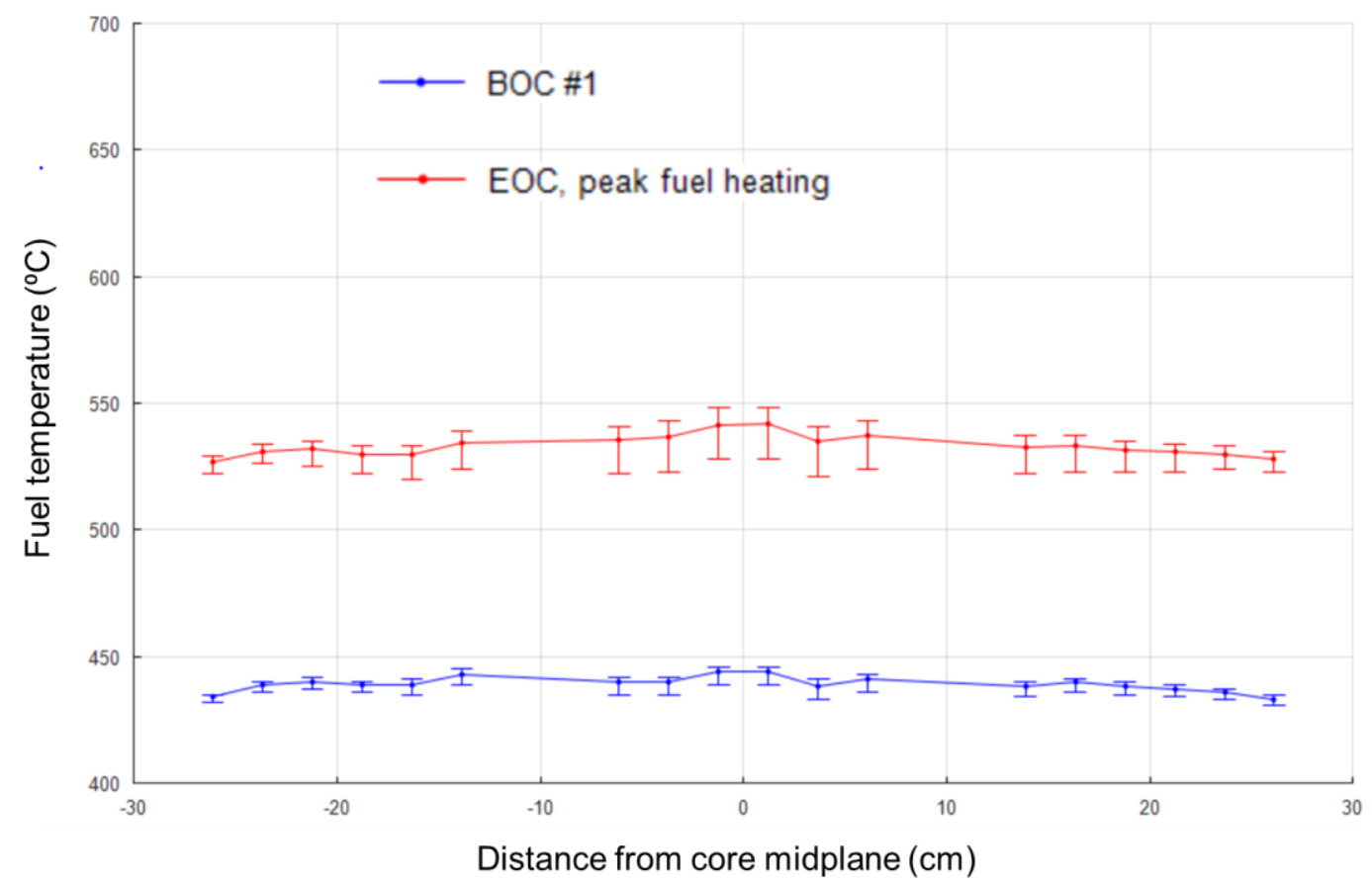

Figure 10. Fuel temperature vs. distance from the core midplane (z) for an outer radial target position at beginning of cycle (BOC) and end of cycle (EOC). Error bars indicate the extreme fuel temperatures at each location.

\section{EXPERIMENT FABRICATION}

\subsection{Sub-capsules Assembly}

A total of 12 sub-capsules were assembled. The parts layout for one sub-capsule is shown in Figure 11. The top image in the figure shows, from left to right, the cup (located inside a handling device that is not part of the assembly), the sub-capsule, the tube, the end cap, the thermometry, and the insulator disks. The bottom left image shows 6 UN kernels loaded inside one fuel cup. The bottom right image shows 4 UN TRISO particles loaded inside a different fuel cup.

Once the fuel specimens were placed in the cup, the sub-capsule was loaded with the cup and the molybdenum tube containing the thermometry. Figure 12 shows a top view of a loaded sub-capsule: insulator disks are placed above the tube and the thermometry is visible at the center of the sub-capsule. The signed sub-assembly fabrication request forms are provided in Appendix A. 


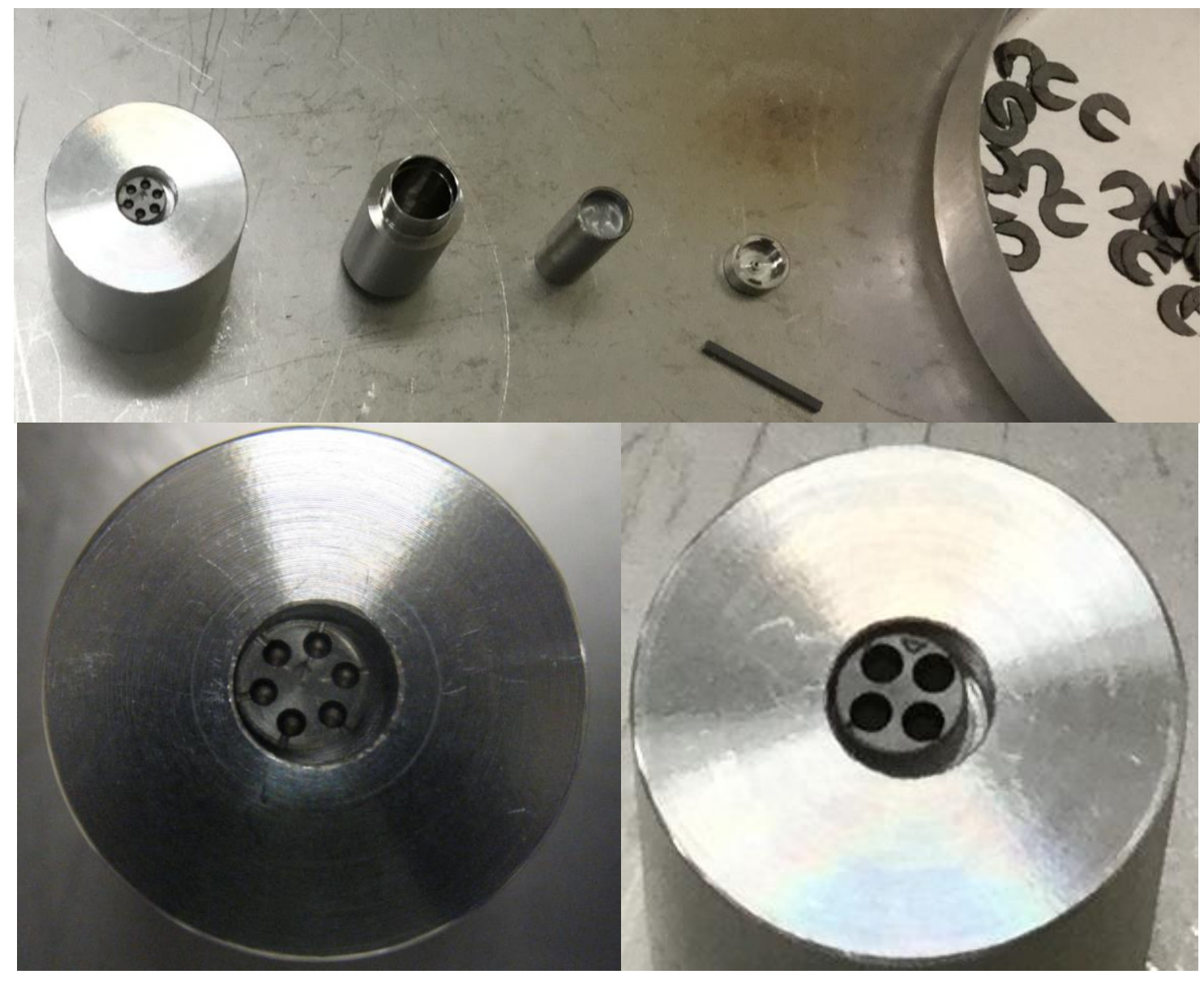

Figure 11. Sub-capsule part layout (top), kernel fuel inside a cup (bottom left), and TRISO particle fuel inside a different cup (bottom right).

All sub-capsule components were dimensionally inspected and cleaned according to HFIRapproved procedures, drawings, and sketches. After assembly of the internal components, all sub-capsule end caps were welded to the sub-capsule bodies using an electron beam weld. The sub-capsule assemblies were then placed inside sealed containers that were evacuated and backfilled with ultra-high-purity helium three times to ensure a pure environment. The containers were placed inside a glove box, which was also evacuated and backfilled with the same gas used in the sealed containers. Each sub-capsule end cap has a small hole that was seal-welded using a gas tungsten arc welding procedure. All welds passed visual examination. Each sub-capsule was then sent for nondestructive examination, which included a bubble test and a helium leak test. All assemblies passed the nondestructive examination. 


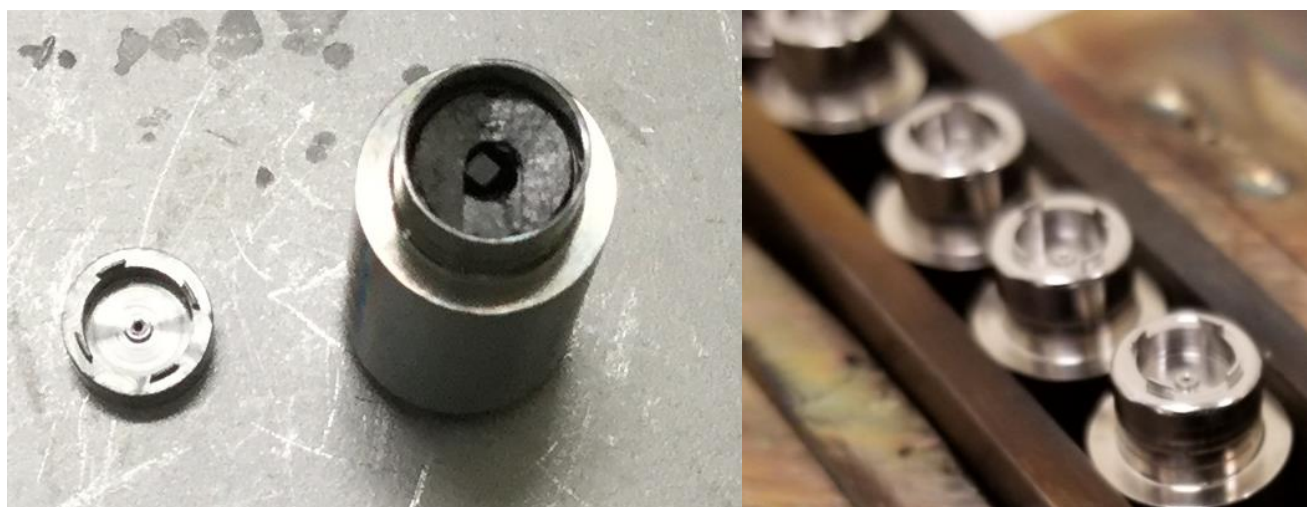

Figure 12. Top view of a loaded sub-capsule without its end cap (left) and welded sub-capsules (right).

\subsection{Target Assembly}

A total of 2 targets, each containing 6 sub-capsules were assembled. The parts layout for one target assembly is shown in Figure 13. As shown in this figure, the target bottom end cap was welded to the target housing prior to loading the sub-capsules. The signed capsule fabrication request forms are provided in Appendix A.

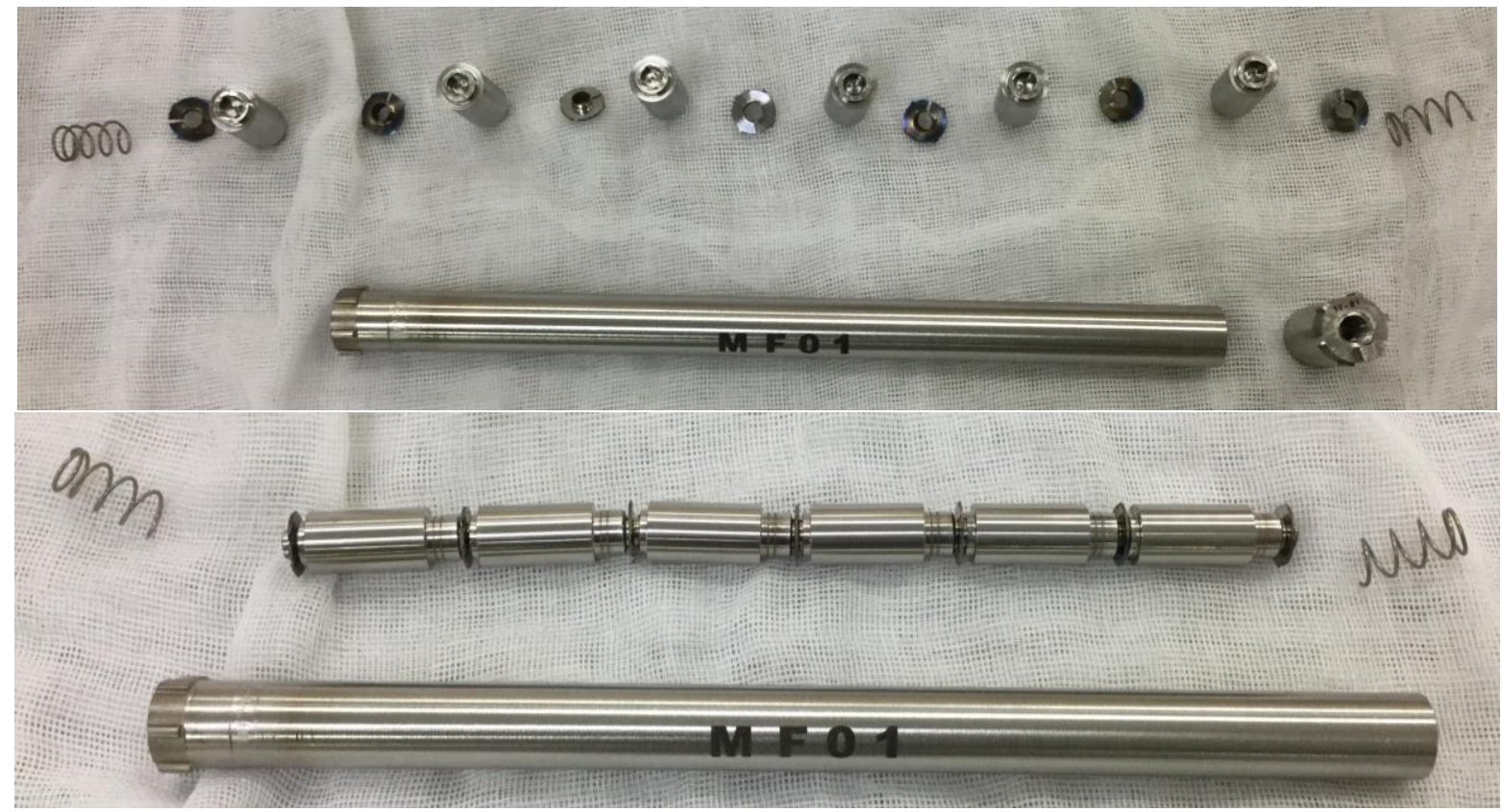

Figure 13. Parts layout for target assembly MF01: individual parts layout (top) and assembly of centering thimbles and sub-capsules (bottom).

All target components were dimensionally inspected and cleaned according to HFIR-approved procedures, drawings, and sketches. After loading the sub-capsules, centering thimbles, and compression springs, the target top end caps were orbital welded to the target housing. The targets were then placed inside a sealed container that was evacuated and backfilled with an ultra-high-purity helium/argon gas mixture three times to ensure a pure environment. The containers were placed inside a glove box, which was also evacuated and backfilled with the same gas used in the sealed container. Each target assembly 
has a small hole in the top end cap that was seal-welded using a gas tungsten arc welding procedure. All welds passed visual examination. Each target assembly was then sent for nondestructive examination, which included a helium leak test, hydrostatic compression at a pressure of 1,035 psi, mass comparisons before and after hydrostatic compression to ensure no water penetrated the target assembly, another postcompression helium leak test, dye penetrant inspection, and radiographic inspection (see Figure 14). All target assemblies passed the nondestructive examination.

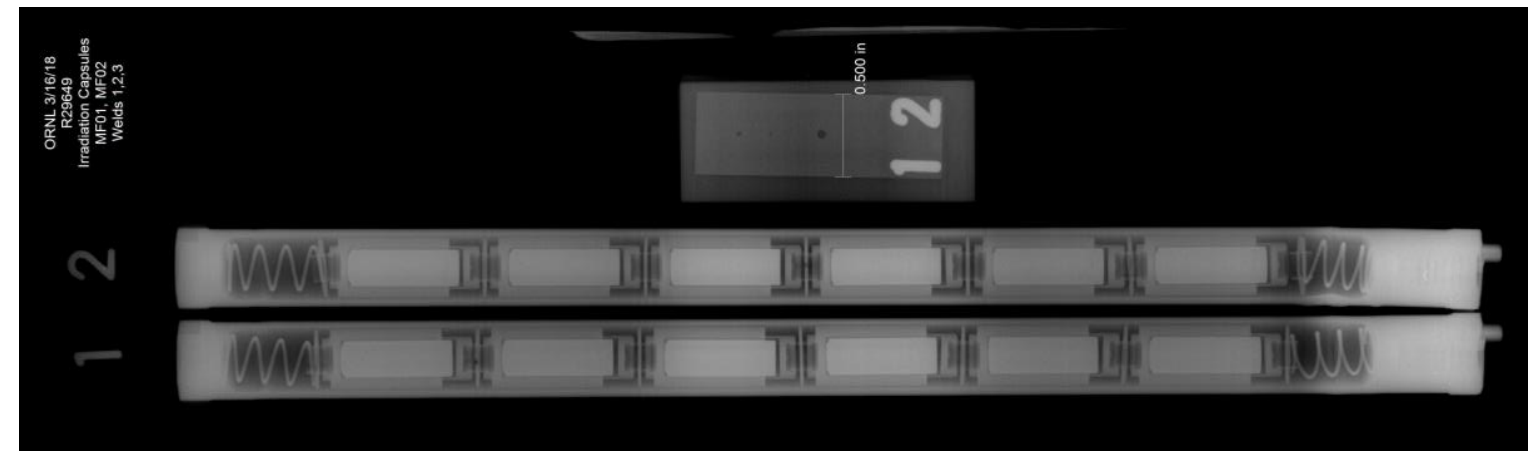

Figure 14. Radiograph of targets MF01 and MF02.

\subsection{Basket Assembly}

The irradiation targets must be loaded into a basket assembly to keep the targets centered within the flow channel in the HFIR small vertical experiment facility. A total of 9 targets were assembled inside the basket with the configuration shown in Figure 1. For this experiment, only two fueled targets (MF01 and MF02) were included. The remaining seven targets (D01 through D07) were stainless steel dummies. Figure 15 shows the parts layout for the basket assembly including the fueled targets, dummies, and the basket itself. Figure 16 shows the insertion of a target in the basket assembly as well as a top-down view of the basket prior after loading all targets. The signed assembly fabrication request form is provided in Appendix A.

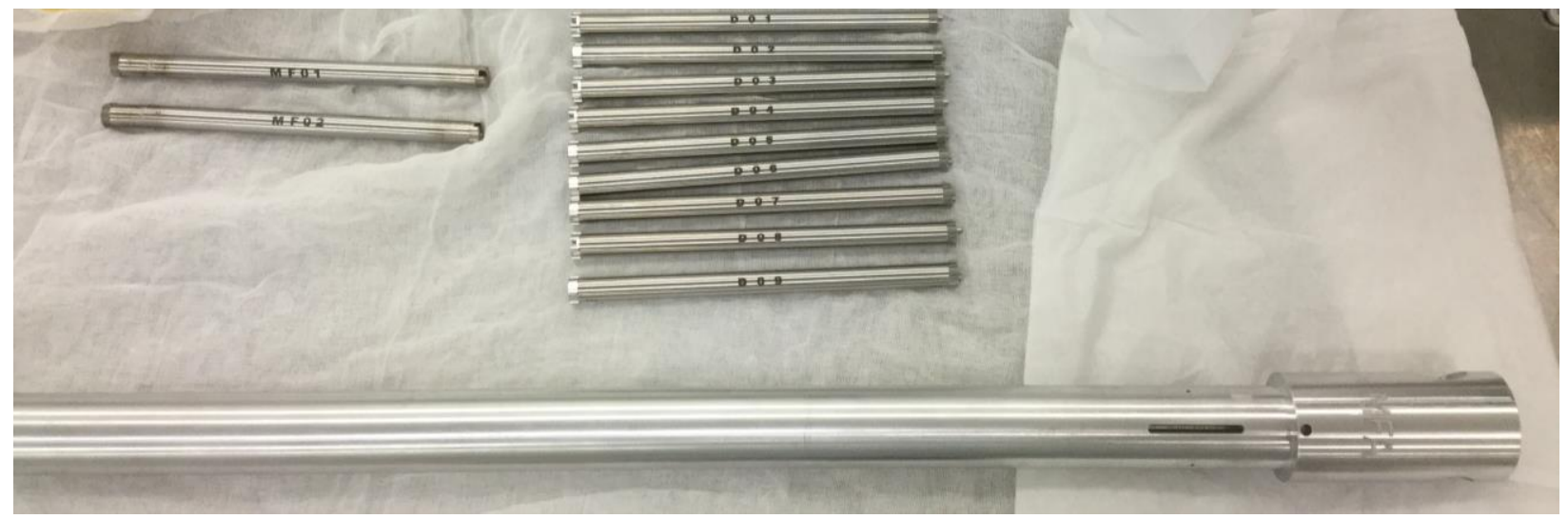

Figure 15. Parts layout for the basket assembly. 

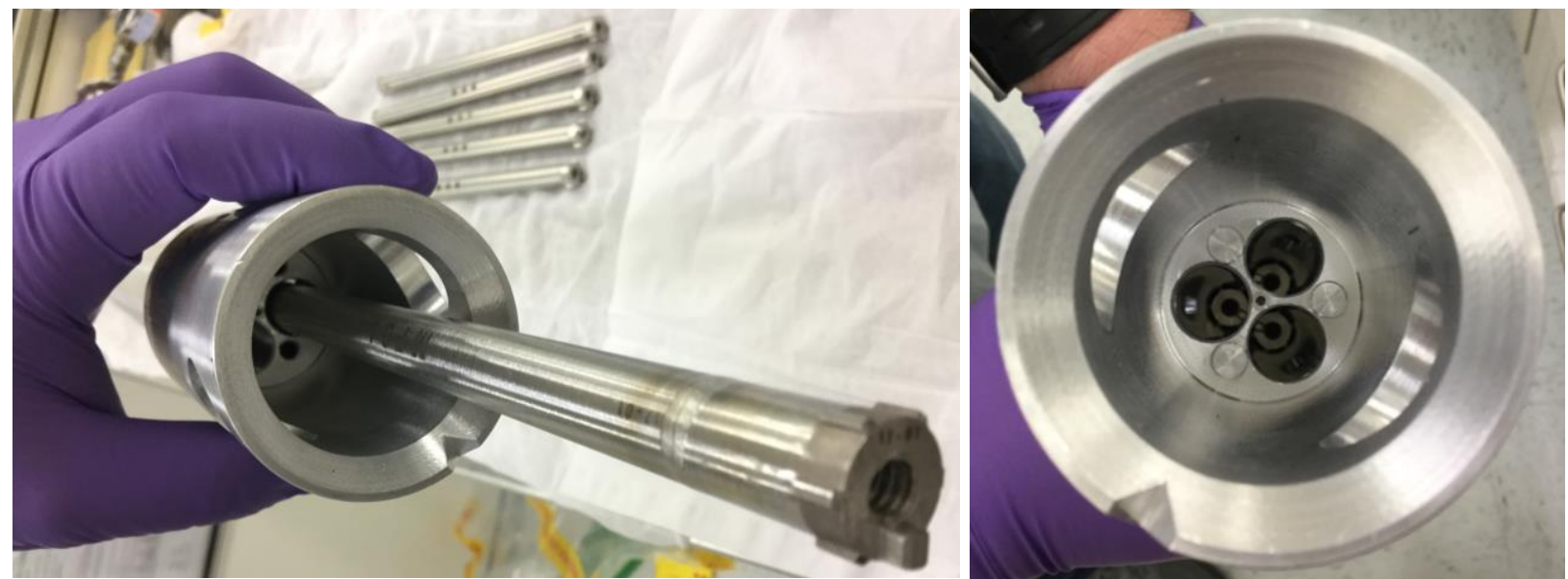

Figure 16. Insertion of a capsule in the basket assembly (left), and top-down view of the basket after loading all targets (right).

\subsection{Fabrication Package and Delivery to HFIR}

Each irradiation experiment requires a fabrication package that is reviewed by an independent design engineer, a lead quality assurance (QA) representative, and a HFIR QA representative before acceptance for insertion into the HFIR. The fabrication package must satisfy the requirements of the experiment authorization basis document (EABD). The irradiation of miniature fuel specimens experiment falls under document EABD-HFIR-2018-001. This document specifies several requirements that the rabbits must satisfy in the areas of

- thermal safety analyses,

- material certification,

- dimensional inspection,

- cleaning,

- assembly procedure,

- sample loading,

- fill gas,

- welding, and

- nondestructive evaluation.

The fabrication package for the basket assembly MFA was reviewed and approved by all parties and accepted by HFIR on May 29, 2018. The final signed acceptance page of the EABD is provided in Appendix A. The basket assembly was inserted during HFIR cycle 480 (June 2018). 


\section{SUMMARY AND CONCLUSIONS}

This report summarizes the design concept and the fabrication of the first series of miniature fuel irradiation experiments supported by the Advanced Fuels Campaign. This first experiment was successfully assembled and delivered to the HFIR for insertion during cycle 480 (June 2018). The experiment contains six different types of UN-based fuel kernels UN TRISO particles, which will be evaluated post-irradiation to determine swelling, fission gas release, and microstructural evolution. The sub-capsules, targets, and basket were successfully assembled, welded, evaluated, and delivered to the HFIR along with a complete QA fabrication package. Pictures of the assembly process are included in this report. Documentation of the experiment fabrication and final acceptance by the HFIR is provided in an appendix. The data that will be obtained from post-irradiation examination of the irradiated specimens will help support the evaluation of new fuel concepts for commercial applications to ultimately improve the accident tolerance and economics of LWRs.

\section{REFERENCES}

1. Campbell, A., et al., Method for analyzing passive silicon carbide thermometry with a continuous dilatometer to determine irradiation temperature. Nuclear Instruments and Methods in Physics Research B, 2016. 370: p. 49-58.

2. Xoubi, N. and R.T. Primm Iii, Modeling of the High Flux Isotope Reactor Cycle 400, ORNL/TM2004/251, Oak Ridge, TN (2005).

3. Chandler, D., Activation and heat generation calculations to support Pu-238 fully loaded target irradiations in inner small VXFs for up to three cycles, C-HFIR-2015-014, Oak Ridge National Laboratory: Oak Ridge, TN (2015).

4. $\quad$ Mcduffee, J.L., Heat Transfer Through Small Moveable Gas Gaps in a Multi-Body System Using the ANSYS Finite Element Software, in Proceedings of ASME 2013 Heat Transfer Summer Conference. 2013: Minneapolis, MN, United States. p. 17783.

5. M. Boivineau, C.C., D. Doytier, V. Eyraud, M.-H. Nadal, B. Wilthan, G. Pottlacher, Thermophysical Properties of Solid and Liquid Ti-6Al-4V (TA6V) Alloy. International Journal of Thermophysics, 2006. 27(507).

6. Cindas, L. Global Benchmark for Critically Evaluated Materials Properties Data. [cited 2016 July, 27]; Available from: http://cindasdata.com.

7. Matweb. Material Property Data. [cited 2016 July 27]; Available from: http://matweb.com/.

8. L. L. Snead, T.N., Y. Katoh, T.-S. Byun, S. Kondo, D. A. Petti, Handbook of SiC properties for fuel performance modeling. Journal of Nuclear Materials, 2007. 371(329).

9. Asme, Boiler and Pressure Vessel Code, in Section II - Materials (Includes Addenda for 2011). 2010, American Society of Mechanical Engineers.

10. S. L. Hayes, J.K.T., K. L. Peddicord, Material property correlations for uranium mononitride: I. Physical properties. Journal of Nuclear Materials, 1990. 171.

11. S. L. Hayes, J.K.T., K. L. Peddicord, Material property correlations for uranium mononitride: II. Mechanical properties. Journal of Nuclear Materials, 1990. 171.

12. S. L. Hayes, J.K.T., K. L. Peddicord, Material property correlations for uranium mononitride: IV. Thermodynamic properties. Journal of Nuclear Materials, 1990. 171.

13. Collin, B., Modeling and Analysis of FCM UN TRISO Fuel Using the PARFUME Code, Idaho National Laboratory: Idaho Falls, ID (2013).

14. S. B. Ross, M.S.E.-G., R. B. Matthews, Thermal conductivity correlation for uranium nitride fuel between 10 and $1923 \mathrm{~K}$. Journal of Nuclear Materials, 1988. 151. 
15. U. C. Nunez, D.P., R. Bohler, D. Manara, Melting point determination of uranium nitride and uranium plutonium nitride: A laser heating study. Journal of Nuclear Materials, 2014. 449.

16. Grafoil Engineering Manual. 2002; 2nd Edition:[Available from: http :/www.graftech.com/wpcontent/uploads/2014/12/GRAFOIL-Engineering-Manual-2nd-Ed.pdf.

17. Mcmurray, J.W., et al., Production of Low-Enriched Uranium Nitride Kernels for TRISO Particle Irradiation Testing, ORNL/SR-2016/268, Oak Ridge National Laboratory: Oak Ridge, TN (2016).

18. Jolly, B., et al., Fabrication and Characterization of DU and LEU UN TRISO Particles, ORNL/LTR-2016/384, Oak Ridge National Laboratory: Oak Ridge, TN (2016). 


\section{APPENDIX A. FABRICATION AND QUALITY ASSURANCE DOCUMENTATION FOR EXPERIMENTS}


Basket ID:

Irradiation Conditions

Small VXF Position

Initial cycle

Assembly Drawing
MFA

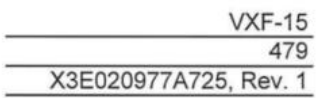

Approvals

\begin{tabular}{|c|c|c|}
\hline & Request & Build \\
\hline Performed by: & Chic Retria & $2030=3 / 26 / 8$ \\
\hline Checked by: & $\frac{\sqrt{3027-28}}{3 / 27 / 18}$ & 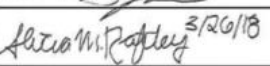 \\
\hline
\end{tabular}

Basket Loading

\begin{tabular}{|c|c|c|c|c|c|c|c|c|c|c|}
\hline Component & Drawing & Rev. & Part & Material & Count & Comment & MAT IR & FAB IR & ID & Mass (g) \\
\hline Basket center section & X3E020977Ä729 & 2 & 1 & Al 6061 & 1 & & $18193^{\circ}$ & 20814 & MFA & 1612.60 \\
\hline \begin{tabular}{|l|} 
Orifice \\
\end{tabular} & X3E020977A674 & 1 & 1 & Al 6061 & 1 & & $20816^{\circ}$ & 20816 & $18-01$ & 175.66 \\
\hline Support web & X3E020977A729 & 2 & 2 & 304 SS & 1 & & 19575 & 20815 & $18-01$ & 35.61 \\
\hline \multirow[t]{3}{*}{ Dummy flux monitor } & \multirow{3}{*}{ X3E020977A722 } & \multirow{3}{*}{2} & \multirow{3}{*}{5} & \multirow[t]{3}{*}{ Al 6061} & \multirow[t]{3}{*}{3} & & \multirow{3}{*}{19348} & \multirow{3}{*}{20819} & 01 & 15.69 \\
\hline & & & & & & & & & 02 & 15.68 \\
\hline & & & & & & & & & 03 & 15.69 \\
\hline Dummy capsule & \multirow{9}{*}{ X3E020977A722 } & \multirow{9}{*}{2} & 4 & 304 SS & 1 & $R-A=1-1$ & 20813 & 20813 & $\mathrm{D} 01$ & 186.46 \\
\hline Dummy capsule & & & 4 & 304 SS & 1 & $R-A=1-2$ & 20813 & 20813 & D02 & 186.40 \\
\hline Dummy capsule & & & 4 & 304 SS & 1 & $R-A=1-3$ & 20813 & 20813 & D03 & 186.66 \\
\hline Dummy capsule & & & 4 & 304 SS & 1 & $R-A=2-1$ & 20813 & 20813 & D04 & 186.17 \\
\hline Experiment capsule assembly & & & 1 & N/A & 1 & $R-A=2-2$ & N/A & 20820 & MF01 & 125.98 \\
\hline Dummy capsule & & & 4 & 304 SS & 1 & $R-A=2-3$ & 20813 & 20813 & D05 & 186.68 \\
\hline Dummy capsule & & & 4 & 304 SS & 1 & $R-A=3-1$ & 20813 & 20813 & D06 & 186.73 \\
\hline Experiment capsule assembly & & & 1 & $\mathrm{~N} / \mathrm{A}$ & 1 & $R-A=3-2$ & N/A & 20820 & MF02 & 126.06 \\
\hline Dummy capsule & & & 4 & 304 SS & 1 & $R-A=3-3$ & 20813 & 20813 & D07 & 186.21 \\
\hline & & & & & & & & & Total Mass & 3428.29 \\
\hline
\end{tabular}

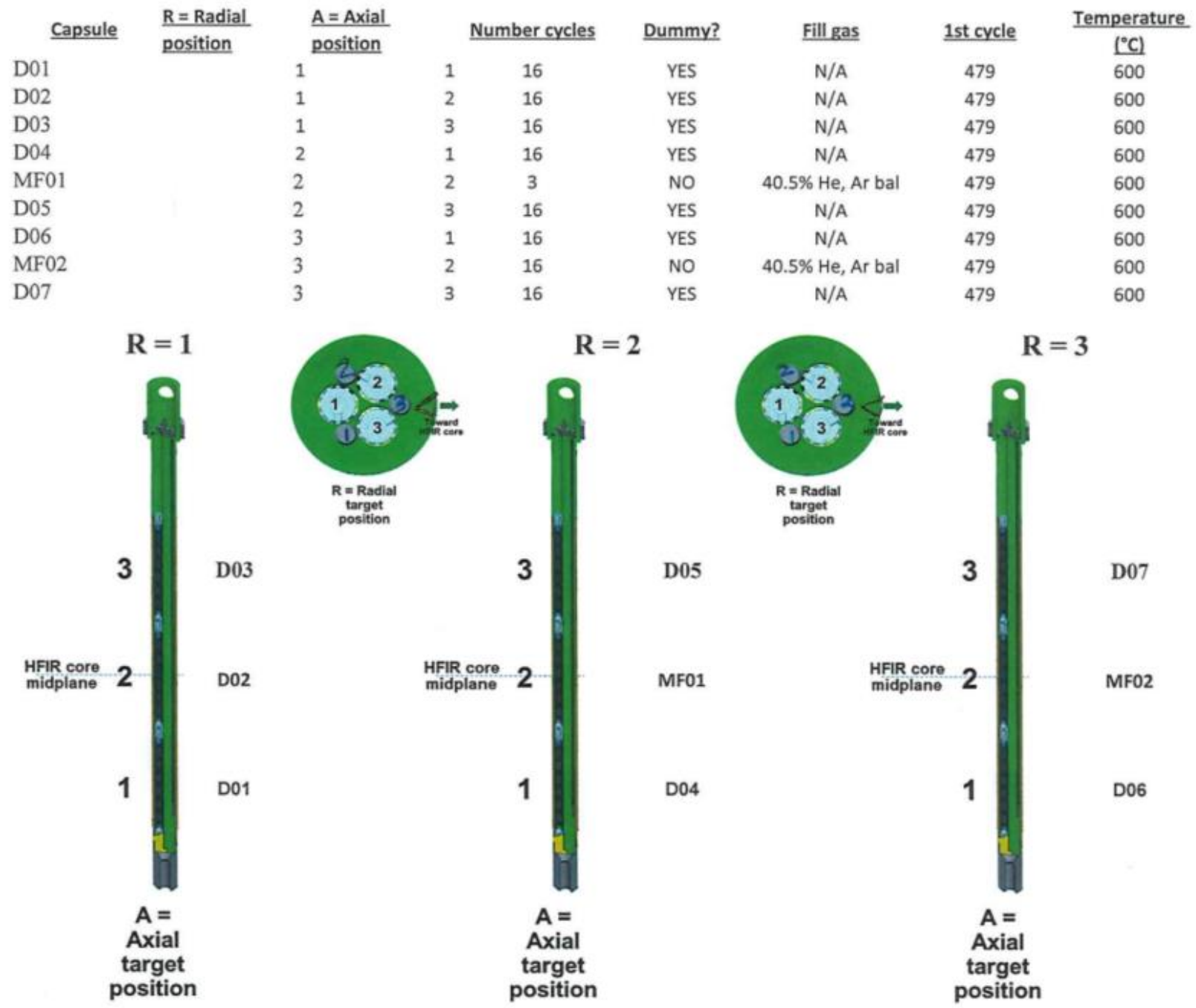


Capsı =abrication Request Sheet

Target ID:

Irradiation Conditions

Irradiation Location (R, A)

Number cycles

First Cycle Goal

Fill Gas

Irradiation Temperature

Assembly drawing

Capsule Fabrication

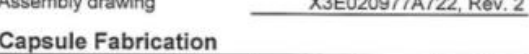

MF01

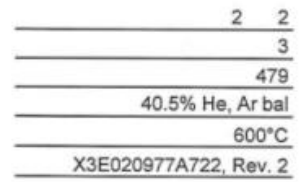

Approvals

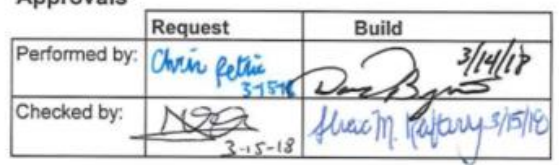

\begin{tabular}{|c|c|c|c|c|c|c|c|c|c|c|}
\hline Component & Drawing & Rev. & Part & Material & Count & Comment & MAT IR & FAB IR & ID & Mass (g) \\
\hline Capsule outer tube & X3E020977A520 & A & 2 & 304 SS & 1 & & $20789^{\circ}$ & 20789 & $17-01$ & 54.1860 \\
\hline Capsule bottom end cap & X3E020977A520 & $A$ & 3 & 304 SS & 1 & & $20790^{\circ}$ & 20790 & $17-01$ & 8.3650 \\
\hline Capsule top end cap & X3E020977A520 & A & 4 & 304 SS & 1 & & $20791^{\prime}$ & 20791 & $17-01$ & 16.0540 \\
\hline \multirow[t]{2}{*}{ Spring } & \multirow{2}{*}{ X3E020977A722 } & \multirow{2}{*}{2} & \multirow{2}{*}{3} & \multirow[t]{2}{*}{304 SS } & \multirow{2}{*}{2} & & \multirow{2}{*}{20810} & \multirow{2}{*}{20810} & 1 & 0.2610 \\
\hline & & & & & & & & & 2 & 0.2620 \\
\hline \multirow[t]{7}{*}{ Centering thimble } & \multirow{7}{*}{ X3E020977A722 } & \multirow{7}{*}{2} & \multirow{7}{*}{2} & \multirow[t]{7}{*}{ Ti-6Al4V } & \multirow{7}{*}{7} & & \multirow{7}{*}{20803} & \multirow{7}{*}{ ' } & $18-01$ & 0.1746 \\
\hline & & & & & & & & & $18-02$ & 0.1708 \\
\hline & & & & & & & & & $18-03$ & 0.1724 \\
\hline & & & & & & & & & $18-04$ & 0.1712 \\
\hline & & & & & & & & & $18-05$ & 0.1713 \\
\hline & & & & & & & & & $18-06$ & 0.1700 \\
\hline & & & & & & & & & $18-07$ & 0.1747 \\
\hline \multirow[t]{6}{*}{ Holder assembly } & \multirow{6}{*}{ S17-13-CER_FUEL } & \multirow{6}{*}{1} & \multirow{6}{*}{1} & \multirow[t]{6}{*}{ N/A } & \multirow{6}{*}{6} & $2-2-6$ & \multirow{6}{*}{ N/A } & \multirow{6}{*}{20821} & $\mathrm{H} 26-01$ & 7.5900 \\
\hline & & & & & & $2-2-5$ & & & $\mathrm{H} 27-01$ & 7.6321 \\
\hline & & & & & & $2-2-4$ & & & $\mathrm{H} 27-02$ & 7.6217 \\
\hline & & & & & & $2-2-3$ & & & H27-03 & 7.6212 \\
\hline & & & & & & $2-2-2$ & & & H27-04 & 7.6335 \\
\hline & & & & & & $2-2-1$ & & & $\mathrm{H} 25-01$ & 7.5530 \\
\hline
\end{tabular}

Holder Sub-Assemblies

\begin{tabular}{|c|c|c|c|c|c|}
\hline Holder ID & & $\begin{array}{c}S=\begin{array}{c}\text { Sub-Assembly } \\
\text { Position }\end{array} \\
\end{array}$ & $\begin{array}{c}\mathrm{R}-\mathrm{A}-\mathrm{S} \\
(\mathrm{R}=\mathrm{Radial} \text { target position, } \mathrm{A}=\mathrm{Axial} \text { target position) }\end{array}$ & \begin{tabular}{c|c} 
Holder \\
diameter $(\mathrm{mm})$
\end{tabular} & Initial \\
\hline H26-01 & 6 & 6 & $2-2-6$ & 9.46 & $D B$ \\
\hline H27-01 & 5 & 5 & $2-2-5$ & 9.49 & $D B$ \\
\hline $\mathrm{H} 27-02$ & 4 & 4 & $2-2-4$ & 9.49 & $D B$ \\
\hline $\mathrm{H} 27-03$ & 3 & 3 & $2-2-3$ & 9.49 & $D$ \\
\hline H27-04 & 2 & 2 & $2-2-2$ & 9.49 & $D B$ \\
\hline H25-01 & 1 & 1 & $2-2-1$ & 9.45 & $D B$ \\
\hline
\end{tabular}


A-4

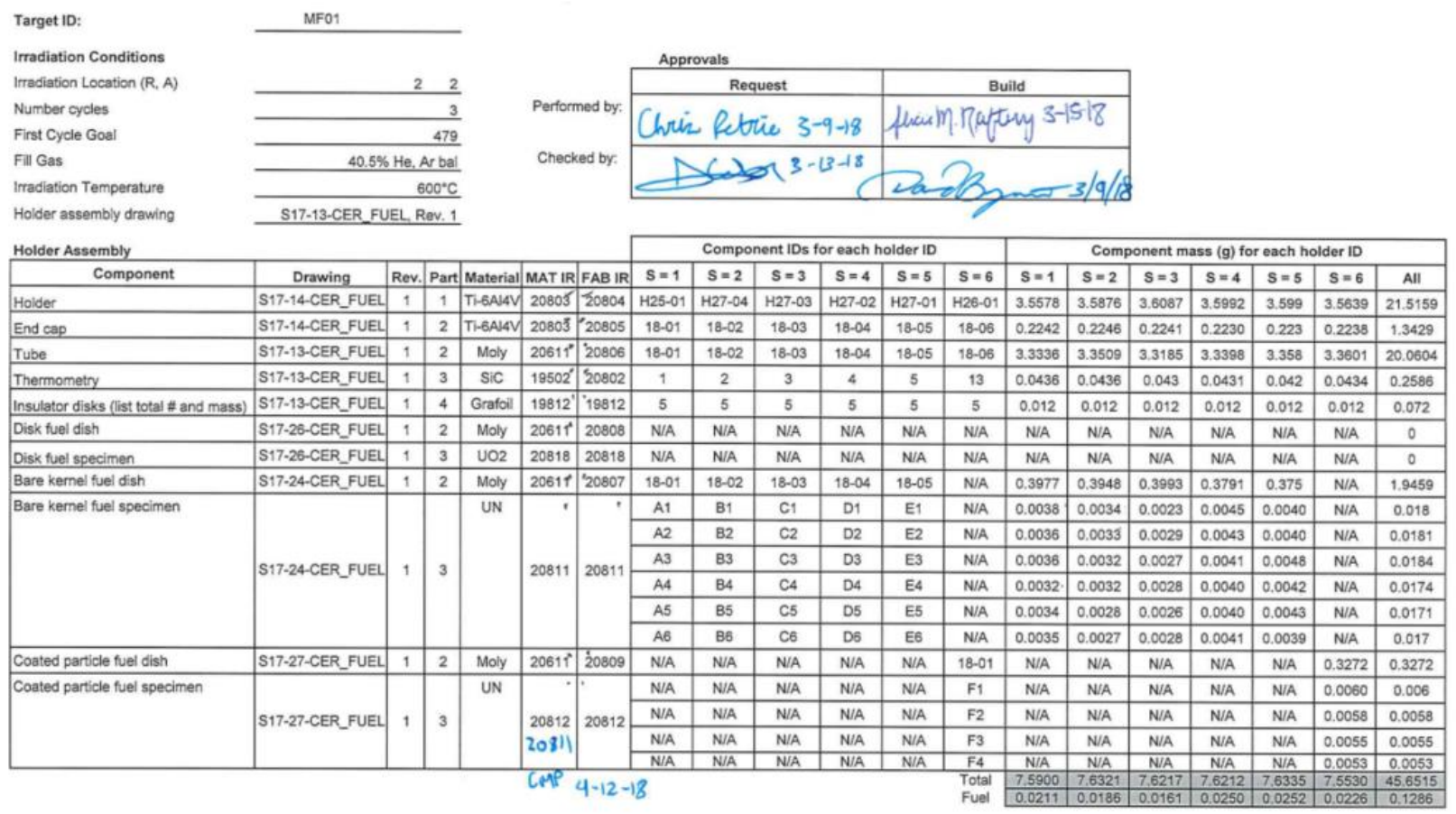




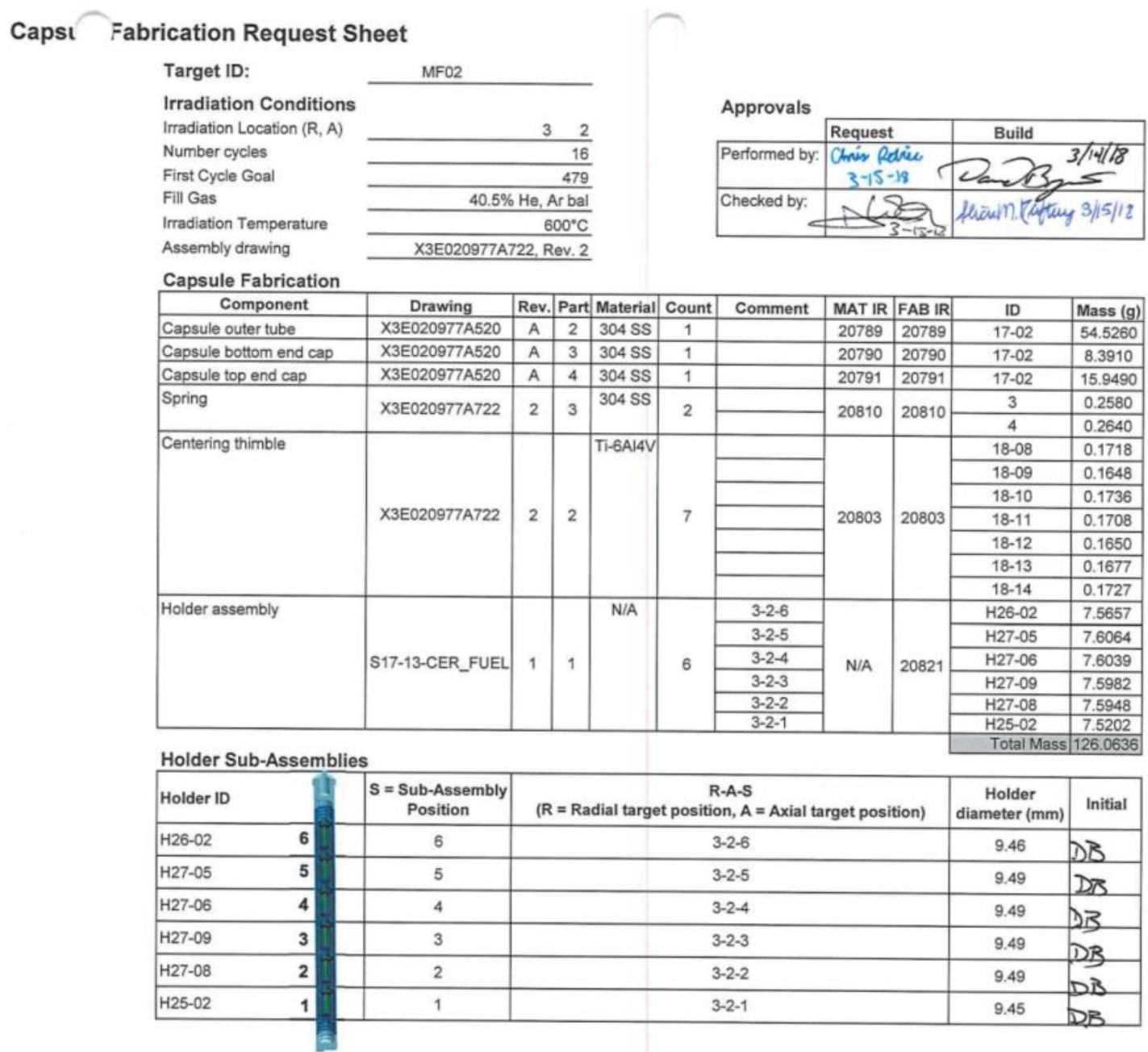

$F$ of 1 Date s. . . $/ 2018$ 
Caps $v$ Fabrication Request Sheet

$\begin{array}{rr}P=0 & 1 \text { of } 1 \\ \text { Dat } \quad 2018\end{array}$

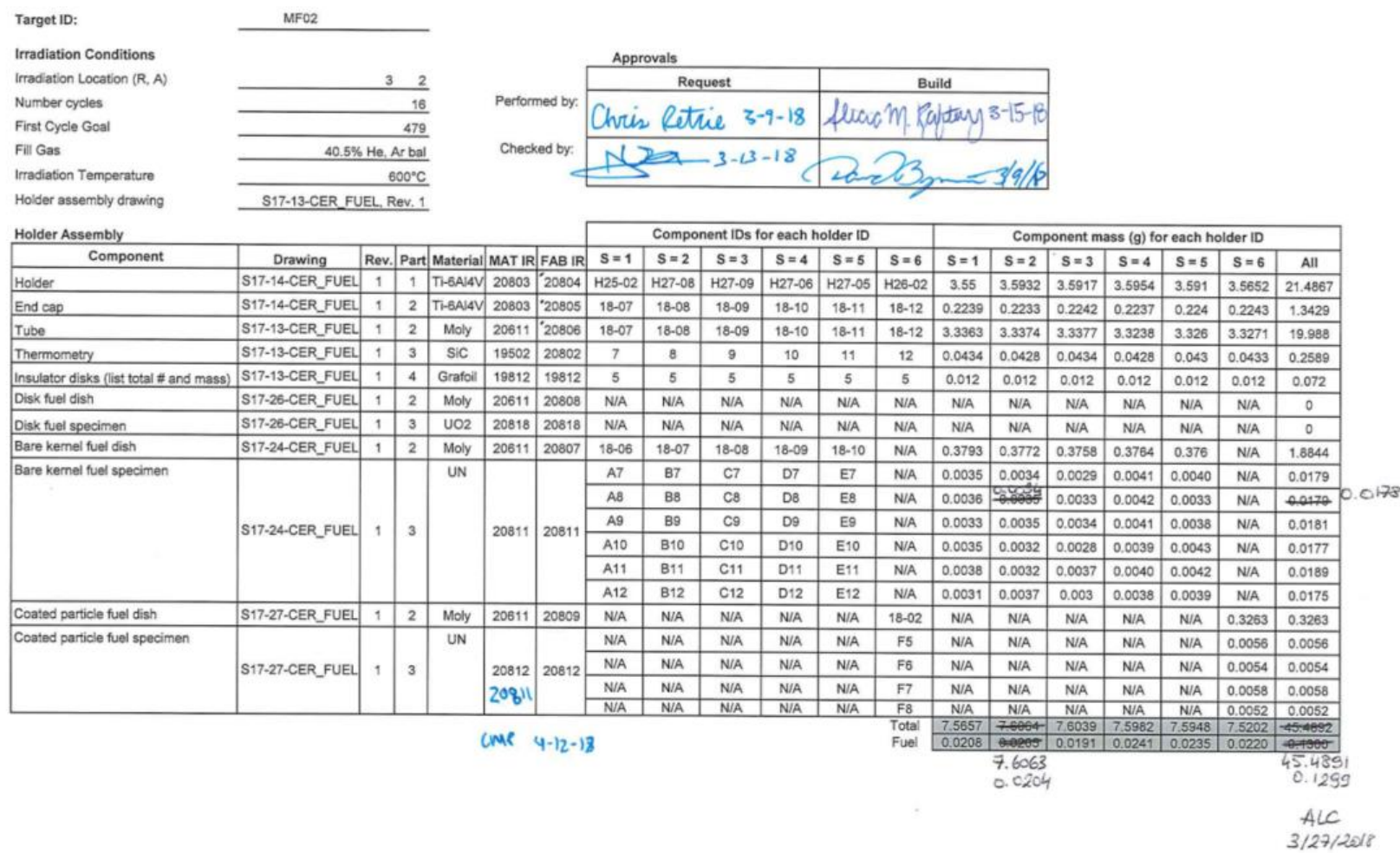




\begin{tabular}{l} 
Section 6: Acceptance for Use of \\
Note: This section is used to document act \\
irradiation. This section is completed after \\
\hline \multicolumn{2}{|c}{ 1. List Applicable Component Identifica } \\
Basket ID: MFA \\
Sub-capsule I.D. \\
H25-01 (2-2-1) \\
H27-04 (2-2-2) \\
H27-03 (2-2-3) \\
H27-02 (2-2-4) \\
H27-01 (2-2-5) \\
H26-01 (2-2-6) \\
H25-02 (3-2-1) \\
H27-08 (3-2-2) \\
H27-09 (3-2-3) \\
H27-06 (3-2-4) \\
H27-05 (3-2-5) \\
H26-02 (3-2-6) \\
\hline
\end{tabular}

2. Approvals (see notes for explanation of signature responsibilities)

Christian Petrie Lead Experimenter

MarkC. VAneE Lead QA

L.C. S. SMITH

RRD NQR Greg $\mathrm{H}_{1} \mathrm{t}_{2}$ E\&FI Staff

N.O.H.ff

RRD Criticality Safety Officer

FULLER, BRIANE (1) HFIR MBA Representative

FULER, BREAWE HFIR Operations (print name)
Chrir Retric

Lead Experimenter (signature)

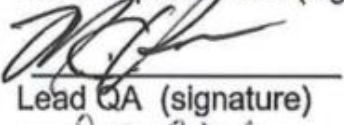

Le sinith

RRD QA (signature)

Yen

E\&FI Staff (signature)

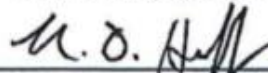

RRD Criticality Safety Officer (signature)

Bine $\sum$ Hollu

HFIR MBA Representative (signature)

Bien 27 tullu

HFIR Operations (signature)
$5-24-18$

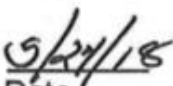

Dáte

$5 / 25 / 18$

Date

$\frac{5 / 29 / 18}{\text { Date }}$

$5 / 21 / 18$

Date

$05 / 29 / 2018$

Date

$\underline{05 / 29 / 2018}$ Date 